\title{
Labor Matching: Putting the Pieces Together
}

\author{
ANTON A. CHEREMUKHIN \\ RESEARCH DEPARTMENT \\ WORKING PAPER 1102
}

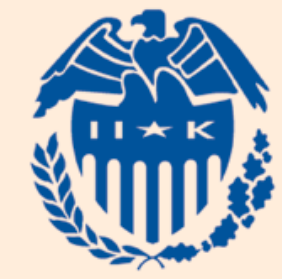

Federal Reserve Bank of Dallas 


\title{
LABOR MATCHING: PUTTING THE PIECES TOGETHER
}

\author{
ANTON A. CHEREMUKHIN
}

\begin{abstract}
The original Mortensen-Pissarides model possesses two elements that are absent from the commonly used simplified version: the job destruction margin and training costs. I find that these two elements enable a model driven by a single aggregate shock to simultaneously explain most movements involving unemployment, vacancies, job destruction, job creation, the job finding rate and wages. The job destruction margin's role in propagating aggregate shocks is to create an additional pool of unemployed at the onset of a recession. The role of training costs is to explain the simultaneous decline in vacancies and slow response of job creation.
\end{abstract} JEL classification: E24, E32, J20, J63.

Keywords: Search, Matching, Job Destruction, Training, Business Cycle.

\section{INTRODUCTION}

The labor search model pioneered by Mortensen and Pissarides (1994 [23], 1998 [24]), the MP model, has attracted considerable attention recently because of its intuitive explanation of equilibrium unemployment. However, Shimer (2005, [30]) has shown that a calibrated stochastic steady state version of the model with only productivity shocks is incapable of quantitatively explaining the behavior of unemployment

Date: This Draft: March 14, 2011. First Draft: March 25, 2009.

Anton Cheremukhin: Federal Reserve Bank of Dallas, 2200 N Pearl St, Dallas TX 75201, chertosha@gmail.com, 214-922-6785. Author thanks Andrew Atkeson, Francisco Buera, Steven Davis, Roberto Fattal Jaef, Hugo Hopenhayn, Oleg Itskhoki, Alex Monge, Paulina Restrepo-Echavarria, Robert Shimer, Jose Silva, Marcelo Veracierto, Venkateswaran Vaidyanathan, Pierre-Olivier Weill and Michael Weiss, as well as participants of the Monetary Economics Proseminar at UCLA, the World Congress of the Econometric Society and the Society for Economic Dynamics for helpful comments. The author is especially thankful to Roger Farmer and Christian Hellwig for their time and advice. All errors are my own. The views expressed in this paper are those of the author and do not necessarily reflect the views of the Federal Reserve Bank of Dallas or the Federal Reserve System. 
and vacancies during the business cycle. Even under an alternative calibration proposed by Hagedorn and Manovskii (2008 [15]) additional exogenous shocks ${ }^{1}$ correlated with productivity shocks are required to fit the data (see Lubik (2009, [21])). This suggests that the simple model studied by Shimer lacks some propagation mechanism.

One shortcoming of this model is that it operates through the job creation margin only, assuming a constant rate of job destruction. The model does not allow firms facing worsened economic conditions to lay off more people. This is at odds with establishment level data studied by Davis and Haltiwanger (1992, [8]) and Davis et. al. (1997, [9]), who document sharp increases in the pace at which firms destroy jobs in recessions, while the response of job creation is mild.

There are several reasons why the job destruction margin has been largely ignored. First, data on worker flows seem inconsistent with the view that the job destruction margin plays an important role. The rate at which workers separate from jobs is almost constant at business-cycle frequencies ${ }^{2}$. One shortcoming of this data is that it is dominated by worker flows that do not immediately affect employment: job-tojob transitions and worker replacement. More recent data from the BLS and JOLTS reaffirm ${ }^{3}$ the view that much of the adjustment in a recession comes through the job destruction margin.

The second reason the literature discounts variations in job destruction is its counterfactual implications for the behavior of the vacancy rate. An increase in the number of workers searching for jobs following a spike in job loss makes it easier for firms to fill positions, thus, encouraging them to open more vacancies. This contradicts the negatively sloped Beveridge curve relationship between unemployment and vacancy rates observed in the data.

In this paper I solve this problem by introducing training costs in addition to recruiting costs. I build on the observation by Silva and Toledo (2009, [32]) that more than 90 percent of costs associated with the job creation process are incurred

\footnotetext{
${ }^{1}$ Exogenous shocks to matching efficiency are an example of such shocks.

${ }^{2}$ See Shimer $(2005,[30])$.

${ }^{3}$ See Davis et. al. (2006, [7]).
} 
after a worker has been hired. Introducing training costs attenuates the effect of reduced market tightness on the incentives of a firm to post vacancies, restoring the Beveridge curve relationship.

The third reason is computational. To explain why some firms choose to layoff workers while others prefer to retain them, a model needs to exhibit match-specific heterogeneity and to keep track of the distribution of job productivities. This makes the computation and analysis of equilibrium behavior a challenging task and calls for convenient simplifying assumptions. In this paper, I propose such a simplifying assumption. I link the size of the support of the distribution of productivities to the number of jobs that can operate in the economy at any point in time. This assumption captures the idea that once the least productive jobs are destroyed, the jobs that survive are better on average. As a result, a persistent decline in aggregate conditions leads to an abrupt but short-lived response of job destruction.

I take advantage of this simplifying assumption to construct a tractable general equilibrium version of the MP model where match-specific heterogeneity leads to endogenous variations in the job destruction rate. I introduce training costs into the model and explore its fit. I find that the two new elements: endogenous job destruction and training costs - enable a model driven by a single aggregate shock of plausible magnitude to simultaneously explain most movements in unemployment, vacancies, job destruction, job creation, the job finding rate, profits and wages. Thus, I find that the original MP model possesses a propagation mechanism that the simplified version does not.

To properly evaluate the fit of the model I expand the set of variables the model seeks to explain. In addition to productivity, unemployment, vacancies and wages used in most of previous studies, I include job creation, job destruction and job finding rates into the analysis. To measure the fit of the model and compare different specifications, I use Bayesian techniques developed for analyzing DSGE models. I form relatively wide priors for parameters of interest and let the data choose parameter combinations that provide the most likely explanation. I then measure the 
fraction of variations in the data that the model can explain under the best parameter combination. Posterior densities of parameters of interest not only tell me which values of parameters are preferred by the data, but also shed light on how well they are identified and, hence, how important they are for the propagation mechanism.

I use this estimation strategy instead of the commonly used calibration strategies for three reasons. First, there is no consensus in the literature regarding many of the parameters of interest. A recent debate between Shimer (2005, [30]) and Hagedorn and Manovskii (2008, [15]) demonstrates how different calibrations of the model can lead to different results. Second, a likelihood function, by giving natural weights to all the moments of the data, provides a tighter measure of success compared to most previous studies. Finally, the Bayesian approach provides a simple tool for understanding which assumptions of the model are important to fit the data and which are not.

Using this estimation strategy, I establish that the explanatory power of the model does not rely on an extreme calibration, like that of Hagedorn and Manovskii, who need relatively small job creation costs to generate large fluctuations in unemployment and vacancies, and a tiny value of the bargaining power of the worker to explain the behavior of real wages. Instead, the model fits the data reasonably well for almost any values of these two parameters.

To better understand the mechanism, I analyze two new elements of the model separately and find that both are crucial for model fit. The first element is that a firm and a worker can each choose to preserve or terminate their relationship based on match profits. This makes firms more eager to destroy jobs when aggregate conditions are worse and the value of a match is lower. The role of the job destruction margin in propagating aggregate shocks is to immediately create an additional pool of unemployed at the very beginning of a recession.

The second element is that job creation costs are a mix of recruiting and training costs. Recruiting costs are costs associated with opening and filling a vacancy, while training costs include all costs specific to the new match incurred conditional on 
finding a worker to fill the vacancy ${ }^{4}$. When more jobs are destroyed and the labor market becomes less tight, it is much easier for firms to find workers. In absence of training costs this would lead to an increase in the number of vacancies. The introduction of training costs attenuates the effect of reduced market tightness on the total cost of creating a new job. Firms facing a lower value of a prospective match and a relatively small decrease in the cost of hiring choose to post fewer vacancies and create fewer new jobs. The dual structure of creation costs explains the decrease in vacancies and the slow response of job creation once jobs have been destroyed.

The contribution of this paper is to construct a tractable general-equilibrium model with match-specific heterogeneity, which not only explains the magnitudes of observed fluctuations in labor market variables, but also generates impulse responses to aggregate shocks reflective of the data. Using the simplicity of the model I derive an analytical relationship between the parameters of the model and the slope of the Beveridge curve. I show how the elasticity of the matching function, the ratio of training to recruiting costs and other parameters jointly determine the slope of the Beveridge curve. This derivation also illustrates why, in this model, the total size of job creation costs does not play a crucial role in determining the response of unemployment and vacancies to aggregate shocks.

My main finding is that a reasonably parameterized labor matching model augmented by a job destruction margin and training costs can simultaneously explain more than three-quarters of fluctuations in unemployment, vacancies, job destruction and the job finding rate, all as a result of a single aggregate shock. The model is also consistent with empirical volatility and cyclicality of productivity, real wages and profits, and generates reasonably slow responses of job creation.

Because the model I construct is deliberately simple, it does not take into account several important aspects of the labor market emphasized in the literature. I abstract from on-the-job search and job-to-job transitions, which account for a large fraction of

\footnotetext{
${ }^{4}$ The idea that creation costs can be a mix of vacancy-specific and match-specific costs was recently revived and discussed by Pissarides (2009, [27]). Non-linear creation costs were also used by Yashiv (2006, [35]) and Rotemberg (2006, [29]).
} 
worker flows ${ }^{5}$. The assumption about the nature of heterogeneity that simplifies the solution of the model also makes employed workers reluctant to search for new jobs. I abstract from the interaction between job destruction and capital adjustment as in den Haan, Ramey and Watson (2000, [10]). Introducing capital and incorporating vintage effects would significantly complicate the analysis. The model also ignores the multi-worker nature of a firm, wage rigidities, collective bargaining and market power, variations in search effort, labor force participation and many other factors ${ }^{6}$. Nonetheless, the model goes a long way toward explaining the response of the US labor market to aggregate shocks. As such it can serve as a useful starting point for further analysis of the effects of the margins mentioned above and for quantitative studies of labor market policies.

The paper is organized as follows. Section 2 lays out the model and derives the slope of the Beveridge curve. Section 3 describes the data and empirical methodology. Section 4 provides a discussion of the results and section 5 concludes.

\section{MODEL}

Before describing the primitives of the model, I provide an explanation for some of the modeling choices I make. In the Mortensen-Pissarides framework, at every point in time, each job is characterized by an individual productivity level. Differences in productivity lead to differences in profits and wages across jobs. A large enough decrease in the productivity of a job leads to termination of the job at the mutual agreement of the worker and the firm. In this model, aggregate shocks have a non-trivial effect on the productivity distribution, which becomes a state variable.

\footnotetext{
${ }^{5}$ See Pissarides (1994, [26]) and Nagypal (2008, [25]).

${ }^{6}$ Introduction of capital and its vintage effects are studied by Caballero and Hammour (1996, [3]), Hornstein et. al. (2005, [18]) and Eyigungor (2008, [11]). Consequences of rigid wages are the focus of Hall (2005, [16]), Farmer and Hollenhorst (2006, [12]), and Gertler and Trigari (2006, [13]). Krause and Lubik (2007, [20]) study decisions of firms with multiple workers, Gertler and Trigari (2006, [13]) and Rotemberg (2006, [29]) study effects of collective bargaining and market power, Veracierto (2008, [34]) incorporates the labor force participation decision, and Meyer (1990, [22]) measures the discouraging effects of unemployment insurance on search effort.
} 
Variations in the number of jobs destroyed are a result of shifts in the productivity distribution over time.

Instead of carrying the productivity distribution, I choose to model the job destruction margin in a somewhat reduced form. I assume that in every period, the idiosyncratic component of productivity, represented in my model by a taste shock, is drawn independently from the same distribution with varying support. The size of the support is equal to the number of existing jobs. This makes the number of jobs a state variable, which characterizes the productivity distribution. I use variations in the support of the distribution to capture the idea that once the relatively unproductive jobs are destroyed, the remaining jobs are better on average. This assumption ensures that a persistent aggregate productivity shock does not lead to a persistent increase in the rate of job destruction.

The model I construct is a real business cycle model with a matching friction. I deliberately simplify the model to concentrate the discussion around the two key elements: endogenous job destruction and training costs. First, I describe the physical environment. Then I explain how employment relationships between workers and firms are formed, operated and terminated. I close the model with a description of the household's problem and equilibrium conditions. I then explain how the incorporation of endogenous job destruction and training costs affects the propagation of shocks.

II.1. Physical Environment. Time is discrete and continues forever. The economy is populated by a unit measure of workers and a large number of firms. Workers can be unemployed searching for a job, headhunting or engaged in a productive employment relationship. I denote the measure of unemployed, $U_{t}$, the measure of headhunters, $X_{t}$, and $N_{t}$ represents the measure of workers engaged in productive activities. Their sum is equal to the total number of workers:

$$
N_{t}+X_{t}+U_{t}=1
$$

Each firm has a blueprint for producing a different variety of the consumption good and needs a worker to be productive. A firm can be in one of three states: matched with a worker and producing, searching for a worker or idle. A firm can hire at 
most one worker, who provides at most one unit of time. As operating firms always demand the maximum amount of time, $N_{t}$ represents both the measure of workers in productive activities and the measure of operating firms. I denote the measure of firms searching for a worker $V_{t}$, which also represents the number of vacancies. The measure of idle firms is sufficiently large so there are always enough potential entrants.

The production technology of a firm is linear in labor so that each worker produces $A_{t}$ units of the final good. $A_{t}$ represents aggregate labor productivity and follows an autoregressive process of order one governed by exogenous productivity shocks $\varepsilon_{t}$ drawn from a standard normal distribution:

$$
A_{t}=A_{s s}^{1-\rho} A_{t-1}^{\rho} e^{\sigma \varepsilon_{t}}, \quad \varepsilon_{t} \in \mathcal{N}(0,1)
$$

where $A_{s s}$ is the steady-state value of productivity, $\rho$ is persistence, and $\sigma$ is the standard deviation of shocks to labor productivity.

New employment relationships are formed through a matching process between firms with openings and unemployed workers. The mass $V_{t}$ of firms that decide to post vacancies are matched with the mass of unemployed workers $U_{t}$ according to a constant returns to scale matching function ${ }^{7}$ :

$$
M_{t}=B U_{t}^{\alpha} V_{t}^{1-\alpha}
$$

where $M_{t}$ is the mass of new employment relationships starting to operate in the next period.

The cost of job creation has two components: a recruiting component includes costs of advertising and interviewing, and a training component includes costs of setting up a working environment and training a worker to meet specific needs. Thus, firms post vacancies at a cost $c$ and then firms matched with workers incur an additional training cost $K$ per match.

\footnotetext{
${ }^{7}$ Given the estimated parameter values, the condition $M_{t} \leq \min \left(U_{t}, V_{t}\right)$ holds in all the simulations with a very high probability.
} 
To cover these costs, firms hire headhunters in a specialized competitive labor market. The total mass of headhunters, $X_{t}$, required to cover job creation costs in period t, satisfies ${ }^{8}$ :

$$
X_{t}=c V_{t}+K M_{t}
$$

I assume that workers are members of a large family that pools income and then distributes it equally to all members. The representative household then maximizes the expected discounted utility of a representative worker, which values consumption and leisure:

$$
E_{0} \sum_{t=0}^{\infty} \beta^{t} u\left(C_{t}, N_{t}+X_{t}\right) .
$$

Consumption aggregator $C_{t}$ is defined over different varieties of the final good:

$$
C_{t}=\int_{0}^{N_{t}} z_{i t} q_{i t} d i
$$

where $z_{i t}$ denotes the idiosyncratic taste shock for variety of firm $i$, and $N_{t}$ is the measure of productive units operating in period $t$. I assume that the taste shock is drawn from a distribution with variable support:

$$
z_{i t}=e^{-g i}, \quad i \in \mathcal{U}\left[0, J_{t}\right]
$$

where $i$ indexes firms uniformly distributed on a closed interval $\left[0, J_{t}\right]$ and $J_{t}$ is the measure of jobs available at the beginning of period $t$.

At the beginning of each period, after aggregate productivity and idiosyncratic tastes become known, firms and workers in existing productive relationships meet and decide whether to preserve the relationship or terminate it. I follow the literature in assuming that if they decide to keep it, they split the surplus using a Nash bargaining solution. I denote $\psi$ the bargaining power of a worker. The threat point of the worker

\footnotetext{
${ }^{8}$ Assuming that headhunters have the same productivity, $A_{t}$, as production workers does not change any of the results. Head-hunters are introduced in order to separate them from production workers, to simplify the exposition and make the interpretation of job creation costs more transparent. In equilibrium headhunters represent a tiny fraction of the labor force.
} 
is to become unemployed and the threat point of the firm is to become idle. Firms and workers discount the future at the same rate.

I denote $\zeta_{t}$ the fraction of jobs that are terminated at mutual agreement of the worker and the firm. Workers join the unemployment pool and start searching for new jobs during the same period. The number of productive units that keep operating in period $t$ is:

$$
N_{t}=J_{t}\left(1-\zeta_{t}\right)
$$

While $N_{t}$ units produce final goods, idle firms open $V_{t}$ new positions and hire $M_{t}$ unemployed workers to fill them. These workers are trained in period $t$ to become productive in period $t+1$. I assume that the training cost, $K$, is split between the worker and the firm in the same proportion as their future surpluses.

The number of jobs carried to the next period is the sum of survivors, $N_{t}$, and new matches, $M_{t}$ :

$$
J_{t+1}=N_{t}+M_{t}
$$

Having described the primitives, technologies and preferences, I now describe the competitive equilibrium in this economy.

II.2. Characterization of Equilibrium. First, I describe the household's problem. The solution of this problem determines how the price of each variety of the final good is resolved. Second, I describe how the outside option of a productive worker is determined. Third, I derive the continuation values of firms and workers, and describe how through bargaining they split the total surplus of the match. Fourth, I discuss the problem firm $i$ and worker $i$ face, when deciding whether to terminate their relationship. Finally, I describe how idle firms choose their recruiting activity. I conclude by defining a competitive equilibrium.

The representative household chooses consumption $q_{i t}$ of each variety $i$ to maximize utility subject to (5) and a budget constraint: 


$$
\int_{0}^{N_{t}} p_{i t} q_{i t} d i=w_{t} X_{t}+\int_{0}^{N_{t}} W_{i t} d i-\psi K M_{t} w_{t}+\Pi_{t}
$$

where all of the wage and profit income net of training costs borne by the workers is spent on final goods produced by firms in the same period. In equilibrium, markets for all varieties of the final good clear:

$$
q_{i t}=A_{t}
$$

Therefore, aggregate profits $\Pi_{t}$ are the sum of individual profits of firms net of headhunting costs:

$$
\Pi_{t}=\int_{0}^{N_{t}}\left(p_{i t} A_{t}-W_{i t}\right) d i-w_{t} c V_{t}-w_{t}(1-\psi) K M_{t} .
$$

Household optimization dictates that output of individual firms is priced using marginal utility of consumption with the price of each variety proportional to household taste for that variety:

$$
p_{i t}=\frac{u_{C_{t}}^{\prime}}{\lambda_{t}} z_{i t}
$$

where $\lambda_{t}$ is the Lagrange multiplier on the budget constraint.

The wages of headhunters $w_{t}$ are set competitively such that members of the household are indifferent between headhunting and being unemployed. Therefore, the wage $w_{t}$ compensates a headhunter for the disutility of work and for the option value of finding a job while being unemployed:

$$
w_{t}=-\frac{u_{X_{t}}^{\prime}}{\lambda_{t}}+\frac{M_{t}}{U_{t}}\left(\Gamma_{t}^{W}-\psi K w_{t}\right)
$$

In equation above, the ratio of matches to unemployment, $\frac{M_{t}}{U_{t}}$, is the probability of finding a job, and $\Gamma_{t}^{W}$ is the worker's expected future benefit from engaging in an employment relationship (see below). The future benefit is taken net of the training cost, which is split between the worker and the firm.

The total value of job $i$ to the worker is the present discounted sum of wages, $W_{i t}$, net of her outside option, $w_{t}$. When deciding whether to preserve the relationship 
with the firm, the worker compares this total benefit to the alternative of walking away and getting nothing. Therefore, the value of job $i$ to the worker, $V_{i t}^{W}$, satisfies:

$$
V_{i t}^{W}=\max \left\{W_{i t}-w_{t}+E_{i t} \beta \frac{\lambda_{t+1}}{\lambda_{t}} V_{i^{\prime} t}^{W}, 0\right\} .
$$

Because of the simplifying assumption that taste shocks are i.i.d., the values of future benefits to the worker are independent of $i$ :

$$
\Gamma_{t}^{W}=E_{i t} \beta \frac{\lambda_{t+1}}{\lambda_{t}} V_{i^{\prime} t+1}^{W}=E_{t} \beta \frac{\lambda_{t+1}}{\lambda_{t}} \max \left\{W_{i^{\prime} t+1}-w_{t+1}+\Gamma_{t+1}^{W}, 0\right\} .
$$

Similarly, the present discounted sum of profits of firm $i$ is compared to the alternative of walking away and getting nothing. The value of the job to firm $i$ satisfies:

$$
V_{i t}^{F}=\max \left\{p_{i t} A_{t}-W_{i t}+E_{i t} \beta \frac{\lambda_{t+1}}{\lambda_{t}} V_{i^{\prime} t}^{F}, 0\right\} .
$$

Likewise, the values of future benefits to firms are all equal:

$$
\Gamma_{t}^{F}=E_{i t} \beta \frac{\lambda_{t+1}}{\lambda_{t}} V_{i^{\prime} t+1}^{F}=E_{t} \beta \frac{\lambda_{t+1}}{\lambda_{t}} \max \left\{p_{i^{\prime} t+1} A_{t+1}-W_{i^{\prime} t+1}+\Gamma_{t+1}^{F}, 0\right\} .
$$

Every period the firm and the worker bargain over the wage, $W_{i t}$, which splits the current surplus in fixed proportions:

$$
W_{i t}-w_{t}=\psi\left(p_{i t} A_{t}-w_{t}\right)
$$

From combining this equation with equations (12) and (13) above, it follows that future and total surpluses are split in the same proportions:

$$
\Gamma_{t}^{W}=\psi\left(\Gamma_{t}^{W}+\Gamma_{t}^{F}\right)=\psi \Gamma_{t},
$$

where joint future surplus $\Gamma_{t}$ is defined as follows:

$$
\Gamma_{t}=E_{t} \beta \frac{\lambda_{t+1}}{\lambda_{t}} \max \left\{p_{i^{\prime} t+1} A_{t+1}-w_{t+1}+\Gamma_{t+1}, 0\right\} .
$$

Since taste shocks (6) are strictly decreasing in $i$ by construction, and prices (10) are linear in tastes; profits, wages and match values are all strictly decreasing in i. Wage bargaining condition (14) and surplus split (15) together imply, that the 
value of a job to the firm and to the worker equal zero simultaneously. Hence, there exists a unique cutoff value $i^{*}$, such that worker $i^{*}$ and firm $i^{*}$ are indifferent between terminating their relationship and keeping it. For all $i>i^{*}$ the worker and the firm mutually agree to terminate their relationship. For all $i \leq i^{*}$ the worker and the firm prefer to keep it. The cutoff $i^{*}=N_{t}$ satisfies:

$$
p_{i t} A_{t}-w_{t}+\left.\Gamma_{t}\right|_{i=N_{t}}=0 \text {. }
$$

This equation determines the number of surviving jobs, $N_{t}$, the cutoff price, $\underline{\mathrm{p}}_{t}=$ $p_{N_{t}, t}$, and the efficient endogenous rate of job destruction, $\zeta_{t}$. Firms and workers terminate their relationships when the sum of current and future surpluses becomes negative.

Finally, free entry of new firms into the labor market guarantees that vacancies are open until their expected marginal costs are equal to their expected marginal benefits:

$$
c w_{t}=\frac{M_{t}}{V_{t}}\left(\Gamma_{t}^{F}-(1-\psi) K w_{t}\right)
$$

where $w_{t}$ is the competitive wage paid to headhunters and $\frac{M_{t}}{V_{t}}$ is the vacancy filling rate, which firms take as given. Thus, exactly enough firms advertise vacancies such that the cost of posting an extra vacancy equals the expected future benefit of a match, net the cost of training the worker if the vacancy is filled.

The assumption that the costs of training the worker are split in exactly the same proportion as the future surplus of the match makes implementation of the planner's solution possible. In Appendix VI.1, I compare the competitive equilibrium to the planner's solution and show that they coincide if, and only if, the Hosios condition is satisfied:

$$
\psi=\frac{\partial M_{t}}{\partial U_{t}} \frac{U_{t}}{M_{t}}=\alpha
$$

A competitive equilibrium of the model economy is a solution to equations (1)-(17), where $\left\{U_{t} ; A_{t} ; M_{t} ; X_{t} ; C_{t} ; z_{i t} ; \zeta_{t} ; J_{t+1} ; q_{i t} ; p_{i t} ; \lambda_{t} ; \Gamma_{t}^{W} ; \Gamma_{t}^{F} ; W_{i t} ; \Gamma_{t} ; N_{t} ; V_{t}\right\}$ are endogenous variables, $w_{t}$ is the numeraire and $\varepsilon_{t}$ is the exogenous shock. 
II.3. Propagation Mechanism. In this subsection, I first provide the motivation for the general equilibrium setup of the model. I augment the description of the model by explaining the choice of preferences with respect to consumption and leisure of the representative household. Then I describe the two key elements of the model, and how they jointly determine the response of unemployment and vacancies to aggregate shocks. Finally, I derive the slope of the Beveridge curve and show how it is affected by the parameters of the model.

Let me make two observations about the properties of the model. First, notice that shocks to aggregate demand, which could be introduced into the model by having an aggregate component of tastes, $Z_{t}$, enter linearly into the price, $p_{i t}$, and, therefore, are indistinguishable from productivity shocks, $A_{t}$. Thus, the model describes the response of the labor market to aggregate shocks, which could come both from the demand and from the supply sides.

Second, compared to the MP model and most of the literature that studies its quantitative implications, this is a general equilibrium model. The advantage of general equilibrium analysis is that it can simultaneously take into account variations in the outside option of the worker due to the consumption-leisure trade-off, as well as unemployment benefits, search costs and other factors. At the same time it decouples parameters that determine the size of variations in the value of a match from parameters that affect average match value. The first set of parameters relates variations in the value of the match to the marginal utility of consumption of a representative household. The second set of parameters pins down the average match value by equalizing revenues a job yields over its lifetime to average costs of job creation.

To capture this idea, I use the following preference specification:

$$
u\left(C_{t}, N_{t}+X_{t}\right)=\frac{C_{t}^{1-\gamma}-1}{1-\gamma}-\varpi\left(N_{t}+X_{t}\right)
$$

This specification borrows infinite Frisch elasticity of labor supply from the model of indivisible labor and employment lotteries of Hansen (1985, [17]) and Rogerson 
$(1988,[28])^{9}$. The only difference from the standard specification is that this utility function is not necessarily consistent with balanced growth ${ }^{10}$. Blanchard and Gali (2010, [2]) show that under the standard specification, when $\gamma=1$ (log consumption), the outside option of the worker moves exactly in line with aggregate productivity, so the value of the match stays constant. As a result, variations in productivity have no effect on any of the labor market variables. Based on this finding Shimer (2009, [31]) argues in favor of rigid wages as a mechanism to explain variations in the labor wedge - the difference between the marginal product of labor and the marginal rate of substitution between consumption and leisure. However, Cheremukhin and RestrepoEchavarria $(2009,[4])$ show that within a similar model, wage stickiness does not help explain the labor wedge and argue in favor of variations in matching efficiency. In the model studied in this paper - a model with endogenous job destruction and matchspecific heterogeneity, neither variations in matching efficiency, nor rigid wages are helpful in generating variations in the labor wedge.

In the absence of a widely accepted explanation for variations in the labor wedge ${ }^{11}$ I use a reduced form specification (18). Parameter $\gamma$ determines the response of the outside option of a worker to variations in productivity and, thus, leads to variations in the labor wedge and in the value of a job. Through variations in values of jobs, this specification has concrete predictions for the behavior of profits that I later use as an independent check of consistency.

I now illustrate the effects of two parameters on the response of the value of a match to variations in productivity. I linearize equations (5), (10) and (15) and substitute them into each other to obtain the elasticity of the value of the match with respect to productivity:

\footnotetext{
${ }^{9}$ See a full derivation for alternative values of labor supply elasticity in Appendix VI.3. Because the Frisch elasticity is not identified separately from other parameters of the model, I fix it at its conventional value.

${ }^{10}$ Note that a model with habit persistence would be equivalent to this specification, while consistent with a long-run balanced growth path.

${ }^{11}$ In yet another approach Karabarbounis (2010, [19]) explores a calibrated model of home production. Substitution between home goods and market goods over the business cycle generates variations in the observed labor wedge, while the true labor wedge remains constant.
} 


$$
\frac{\hat{\Gamma}_{t}}{\hat{A}_{t}} \approx \frac{1-\gamma}{\gamma+\delta} \rho(1+\delta),
$$

where $\hat{x}_{t}$ denotes percentage deviations from steady-state ${ }^{12}, \rho$ denotes persistence of the productivity shock, and $1+\delta=\frac{z_{\max }}{z_{\min }}$ is the difference between the highest and the lowest taste shock.

It is clear that curvature of preferences, $\gamma$, plays a decisive role in the response of match value to variations in productivity. When $\gamma=1$, there is no response in any of the labor market variables. When $\gamma \leq 1$, the value of the match, employment and match profits all fall in response to a decline in productivity. Parameter $\delta$, on the other hand, is closely related to the average match value and to the average cost of job creation. It has little effect on the size of variations in match values. As a result, the response of the labor market to aggregate shocks is sensitive to $\gamma$ and not very sensitive to $\delta$.

Now, I move to the discussion of how the two key elements of the model work. The job destruction margin is the first key element of the model. Figure 1 depicts the price distribution as a function of the firm index $i \in\left[0, J_{t}\right]$. The cutoff price level, $\underline{\mathrm{p}}_{t}$, corresponds to the number of productive jobs, $N_{t}$. A fraction $\zeta_{t}$ of available jobs that are not worth operating according to equation (16) are terminated at the mutual agreement of the worker and the firm. In a steady-state, all of the destroyed jobs are replaced by new matches.

A negative productivity shock $\varepsilon_{t}$ leads to a persistent decrease in productivity $A_{t}$ and results in a decrease in expected future benefits, $\Gamma_{t}$. This shifts the cutoff price upward and leads to a spike in job destruction and a consequent increase in unemployment:

$$
\frac{\hat{U}_{t}}{\hat{A}_{t}} \approx-\frac{1-U_{s s}}{U_{s s}} \frac{1-\gamma}{\gamma+\delta}
$$

where $U_{s s}$ is the steady-state unemployment rate. The response of unemployment is determined by the same two parameters mentioned above, $\gamma$ and $\delta$, as well as by the average unemployment rate.

\footnotetext{
${ }^{12}$ Full derivation of the steady-state and the linearized equations are described in Appendix VI.2.
} 


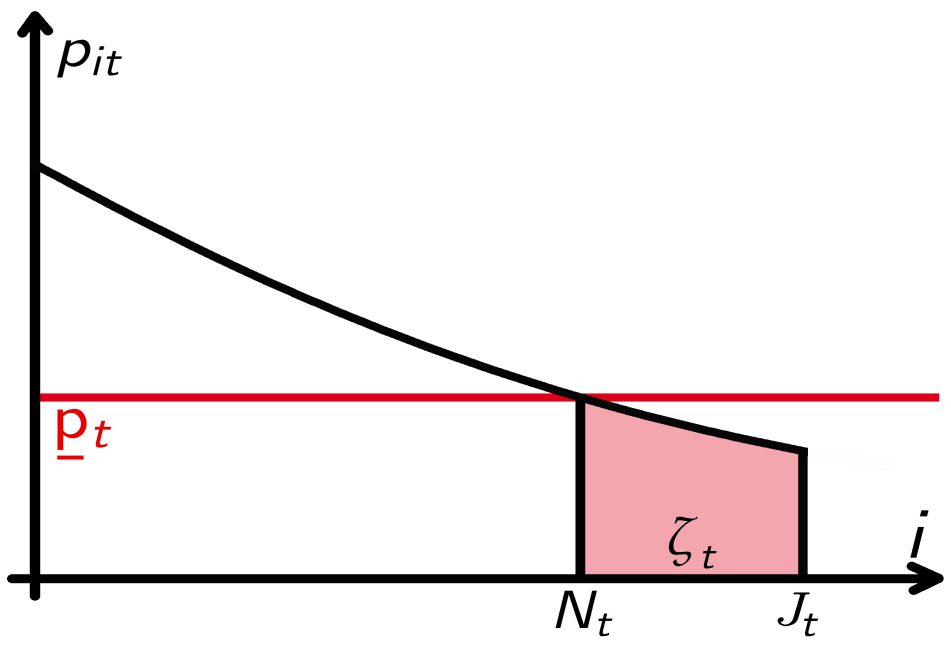

Figure 1. Price Distribution and the Cutoff Price.

Training costs are the second key element of the model. They help explain the response of vacancies and job creation to productivity shocks. To demonstrate the effect of training costs, I linearize equation (17) and substitute in the matching function (3):

$$
\hat{U}_{t}-\hat{V}_{t}=\frac{\hat{\Gamma}_{t}}{\alpha(1-\varphi)},
$$

where $\alpha$ is the elasticity of the matching function, $\varphi=\frac{\varphi_{2}(1-\psi)}{\varphi_{2}(1-\psi)+1-\varphi_{2}}$ is the fraction of training costs incurred by the firm in proportion to total costs incurred by the firm, and $\varphi_{2}=\frac{K M_{s s}}{c V_{s s}+K M_{s s}}$ is the fraction of training costs in total costs of job creation. This equation shows how training costs modulate the response of labor market tightness to variations in the value of a match.

When training costs are absent, $\varphi \rightarrow 0$, the response of market tightness to changes in prospects of future profits is small. A negative productivity shock leads to a sharp increase in unemployment, which through a mild response in market tightness leads to an increase in the vacancy rate. Thus, when most of the costs are recruiting costs, a sharp increase in unemployment makes workers much easier to find, encouraging firms to post more vacancies. 
When, on the contrary, most of the costs are training costs, $\varphi \rightarrow 1$, a decrease in the value of the match leads to a sharp decrease in market tightness. Training costs attenuate the response of total costs to market tightness, discouraging firms from opening vacancies in a recession.

Combining equation (21) with equations (19) and (20) I derive the slope of the Beveridge curve:

$$
\frac{\hat{V}_{t}}{\hat{U}_{t}}=1-\frac{1}{\alpha(1-\varphi)} \frac{U_{s s}}{1-U_{s s}} \rho(1+\delta) .
$$

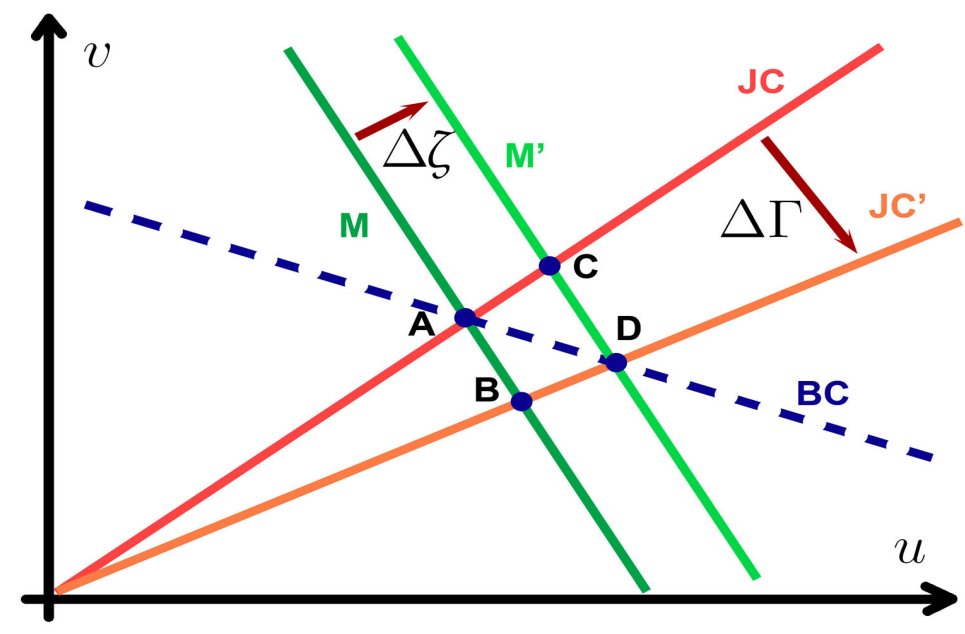

Figure 2. Beveridge Curve.

The slope of the Beveridge curve is strongly affected not only by the elasticity of the matching function, $\alpha$, but also by the relative size of training costs, $\varphi$. Parameter $\gamma$, according to equation (20), is the main determinant of the size of movements along the Beveridge curve, but has no effect on the slope of the curve. To illustrate the combined effect of the job destruction margin and training costs, I use a comparative statics exercise. I look at three cases: constant exogenous job destruction, as well as endogenous job destruction with and without training costs.

To give a numerical illustration, I set tentative values for the key parameters. One can infer the elasticity of the matching function directly from comparing the volatilities of market tightness and the job finding rate following Shimer $(2005,[30])$. 
I use this method to set $\alpha$ to 0.72. I build on evidence from Silva and Toledo (2009, [32]) to infer the size of total costs and its split into recruiting and training costs. Using this evidence, I set $\delta$ to 0.8 , so that total job creation costs represent 40 percent of the quarterly wage of a typical employee, and $\varphi$ to match the observation that training costs account for 93 percent of job creation costs incurred by firms. I also set $\rho$ to 0.92 - the typical value for persistence of productivity shocks in the business cycle literature, and $U_{s s}$ to 5.6 percent - the historical average unemployment rate in the U.S.

First, when jobs are destroyed at an exogenously given rate, the Beveridge curve coincides with an isoquant of the matching function. Its slope is determined exclusively by the elasticity of the matching function, $\alpha$ :

$$
\frac{\hat{V}_{t}}{\hat{U}_{t}}=\frac{-\alpha}{1-\alpha}=-2.57
$$

Second, when firms are allowed to choose whether to destroy jobs based on future profits, and all job creation costs are recruiting costs, the Beveridge curve is positively sloped:

$$
\frac{\hat{V}_{t}}{\hat{U}_{t}}=1-\frac{1}{\alpha} \frac{U_{s s}}{1-U_{s s}} \rho(1+\delta)=0.86 .
$$

Increasing the fraction allocated to training costs solves this problem. When training costs are set to correspond to 93 percent of job creation costs, leaving 7 percent to recruiting costs, the predicted slope of the Beveridge curve comes close to the slope of -1 - the slope of U.S. unemployment and vacancy data.

$$
\frac{\hat{V}_{t}}{\hat{U}_{t}}=1-\frac{1}{\alpha(1-\varphi)} \frac{U_{s s}}{1-U_{s s}} \rho(1+\delta)=-0.95 .
$$

Figure 2 illustrates in the unemployment-vacancy space how the slope of the Beveridge curve is determined by a combination of shifts in the matching curve and the job creation curve. Let point $\mathrm{A}$ be the original steady-state. In case I, when job destruction is given exogenously, variations in the value of the match shift the job creation curve (21) clockwise. The economy moves along the isoquant of the matching function (3) to point B. In case II, when job destruction is endogenous, but training 
costs are absent, a spike in job destruction shifts the matching curve upwards. This shift is much larger than the shift in the job creation curve, so the economy ends up in point C. Finally, when training costs are a large fraction of total costs, an aggregate shock leads to a concerted movement in both the matching curve and the job creation curve, leading the economy to point D. This corresponds to case III, with the slope of the Beveridge curve resembling the behavior of the data.

The dynamic response of the calibrated model is summarized by impulse response functions to a productivity shock depicted in Figure 3. It works as follows: A negative productivity shock lowers contemporaneous profits of firms leading to a sharp increase in job destruction. As more workers lose their jobs the number of unemployed workers increases, making the labor market less tight. A decline in contemporaneous productivity also leads to a decline in expected future profits. This lowers the benefits to firms of creating new jobs and, because of the mild response of job creation costs, significantly undermines their incentives to open vacancies. The number of vacancies falls. As the number of employment opportunities shrinks due to lower productivity, the number of newly created jobs does not respond much.

After a sharp employment adjustment in the first period, the least productive jobs have already been destroyed and the job destruction rate quickly returns close to its original level. As productivity slowly recovers, the cutoff price for job destruction slowly returns to its original level. As firms see an increase in future profits, they start opening more vacancies and creating more jobs.

\section{Empirical Methodology}

To explore the ability of the model to fit the data I use recently developed Bayesian methods for analyzing DSGE models. ${ }^{13}$ This methodology has several advantages when compared to commonly used calibration strategies. In the context of vigorous debates over parameters of the standard matching model, the Bayesian framework

\footnotetext{
${ }^{13}$ A survey of these methods is provided for instance by An and Schorfheide (2007, [1]).
} 

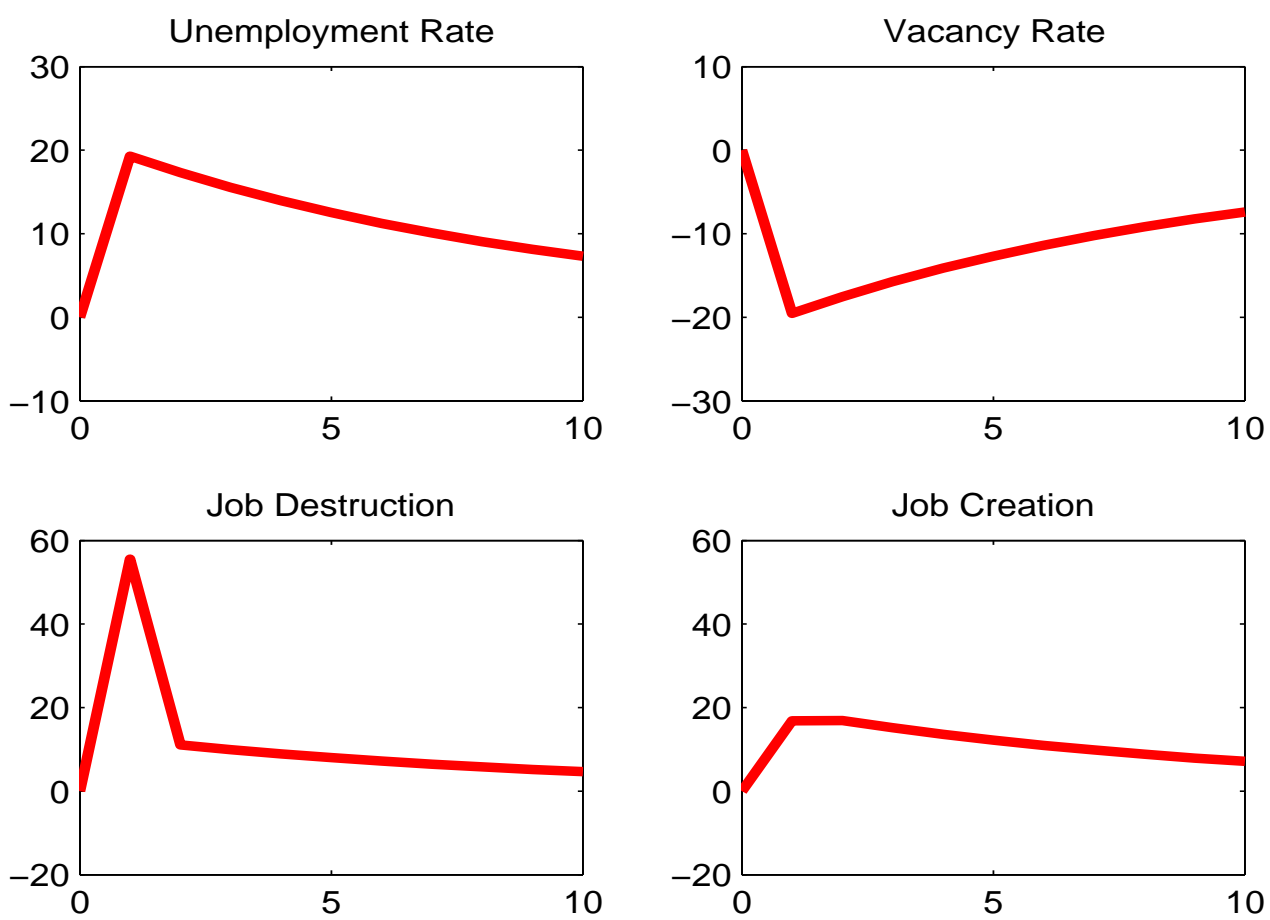

Figure 3. Impulse Responses to a $1 \%$ Negative Productivity Shock.

allows me to remain agnostic. I let the data choose a calibration that is most likely to explain its behavior.

The second advantage of this methodology is that a likelihood function gives natural weights to different moments of the data instead of focusing on just a few. In addition, setting relatively wide priors allows me to conduct a sensitivity analysis of model performance to the parameter combination. If I find that a posterior estimate is as wide as the prior, then the exact value of the corresponding parameter is not important for explaining the data. Conversely, if a posterior estimate is very narrow, this means that model dynamics are very sensitive to the exact calibration of a parameter.

In this section, I describe the strategy that I use to evaluate the model. I also discuss data sources and prior distributions. First, I solve for the steady-state of the model. I then log-linearize the equations of the model around the steady-state and solve the resulting system of linear forward-looking equations using a method 
developed by Sims $(2002,[33])$. This gives me the state-space representation of the model:

$$
\begin{gathered}
X_{t}=F X_{t-1}+G \varepsilon_{t} \\
Y_{t}=H X_{t}+v_{t},
\end{gathered}
$$

where $X_{t}$ is the vector of state variables and $Y_{t}$ is the vector of observables. I assume that the innovation to labor productivity, $\varepsilon_{t}$, is the only exogenous shock in the model. I attribute all the residual variation in observed fluctuations to a vector of measurement errors, $v_{t}$. The fraction of variations in $Y_{t}$ explained by the model is represented by $H X_{t}$ and the unexplained component is captured by the error term. To allow for enough variation in the data and to avoid stochastic singularity, I assume there are as many sources of measurement error as there are observables so that each measurement equation has its own error term ${ }^{14}$.

I treat the model as the data-generating process and use the Kalman filter to construct the likelihood function of the data conditional on parameters. I combine the likelihood function with the prior distribution of parameters to obtain the posterior distribution of parameters and use the random-walk Metropolis-Hastings algorithm to explore it numerically ${ }^{15}$. I then use the Kalman filter to obtain smoothed estimates of the shock process for labor productivity using parameter values at posterior mode.

III.1. Data. For estimation, I use seven observables: unemployment, vacancies, job destruction, job creation, the job finding rate, real wages and labor productivity. All data are quarterly, seasonally adjusted for the period 1951:1 - 2009:4 ${ }^{16}$. The unemployment series is the unemployment rate for those older than age 16, provided

\footnotetext{
${ }^{14}$ To avoid stochastic singularity I need at least as many shocks as observed variables. If I include productivity shocks, I can exclude one of the measurement errors. I choose not to do so because that would imply a prior choice of the variable I want the model to explain exactly. I choose to remain agnostic about the choice of variables the model can best explain.

${ }^{15}$ The algorithm is extensively discussed in Geweke (1999, [14]). I use the open source DYNARE software developed by Collard and Juillard (2003, [6]) and collaborators.

${ }^{16}$ To avoid merging data series from different sources for job creation, job destruction, job finding rate and vacancies, I could restrict selection to a time interval ending in 2004:4 and exclude the
} 
by the BLS. The vacancy series is the index of help-wanted advertisements provided by the Conference Board before 2001, merged with JOLTS data after 2001. The series for real wages is constructed by dividing average hourly earnings in private nonfarm payrolls by the consumption price index.

As a proxy for job destruction and job creation, I use destruction and creation rates in manufacturing constructed by Davis et. al. (2006, [7]). Davis, Faberman and Haltiwanger also provide series for all sectors for a much shorter period of time. The series for manufacturing and for all sectors have notably different volatilities, but a correlation close to one (see Appendix). I use this observation to scale the series for manufacturing to represent the whole economy. For the period after 2005, I augment the series with rates of job loss in contracting establishments and job gains in expanding establishments in manufacturing supplied by BED. Finally, I use the job finding rate series computed from CPS data by Shimer (2005, [30]) and augment it for the period after 2007 with the transition rate from unemployment to employment constructed from CPS data.

I use the series for labor productivity, measured as real output per worker in the non-farm business sector. This series is constructed by the BLS from the National Income and Product Accounts and the Current Employment Statistics. For a consistency check, I also construct data series for profits and output. For the profits series, I take nominal corporate profits before taxes from the BEA and divide them by the nominal value of GDP. The output series is the real GDP index provided by the BEA divided by the labor force. I apply the Hodrick-Prescott filter with smoothing parameter 1600 to detrend all series.

III.2. Priors. There are nine structural parameters in the model, of which $\{g, B, c, K\}$ are hard to directly compare with micro estimates. Instead of estimating them directly, I construct an alternative set of steady-state values that I then treat as parameters. I define $u=U_{s s}$ - the steady-state unemployment rate, $s=\zeta_{s s}$ - the job destruction rate, $\varphi$ - the fraction of training costs in total job creation costs incurred recession of 2008. This would not change any of my conclusions, so I prefer to include the most recent recession episode. 


\begin{tabular}{|l|c|c|c|c|}
\hline Parameter & & Density & Mean & Std. Dev. \\
\hline Discount factor & $\beta$ & Fixed & 0.99 & - \\
\hline Matching elasticity & $\alpha$ & Beta & 0.5 & 0.2 \\
\hline Bargaining power of worker & $\psi$ & Beta & 0.5 & 0.2 \\
\hline Curvature of demand & $\gamma$ & Beta & 0.5 & 0.2 \\
\hline \hline Unemployment rate & $u$ & Fixed & .056 & - \\
\hline Job destruction rate & $s$ & Gamma & 0.03 & 0.015 \\
\hline Fraction of training costs & $\varphi$ & Beta & 0.8 & 0.1 \\
\hline Total costs & $\phi$ & Beta & 0.3 & 0.15 \\
\hline \hline Persistence of productivity & $\rho$ & Beta & 0.5 & 0.2 \\
\hline
\end{tabular}

TABLE 1. Prior Distributions

by firms and $\phi$ - the sum of recruiting and training costs per employee incurred by a firm as a fraction of their quarterly wage. I then use the fact that conditional on the rest of the parameters, there is a one-to-one mapping between $\{g, B, c, K\}$ and $\{u, s, \varphi, \phi\}$.

Prior distributions are reported in Table 1. I choose prior means based on values used in previous studies. I make the priors uninformative by setting prior standard deviations to relatively large values whenever possible. This allows me to remain agnostic and let the data choose the parameter combination that is most likely to capture the dynamic properties of the data. For parameters with support on the unit interval, I use the Beta distribution and for real-valued parameters I use the Gamma distribution.

I set the discount factor $\beta$ to 0.99 . The unemployment rate is fixed at its historical mean of 5.6 percent. Based on evidence from Silva and Toledo (2009, [32]), I set total cost of job creation to 30 percent of the quarterly wage of a new hire and the fraction of training costs to 80 percent of the job-creation amount. I allow for large variations in both of these values. 
I set the steady-state job destruction rate at 3 percent to match the average flow from employment to unemployment during a quarter. ${ }^{17}$ I choose to be completely agnostic about the bargaining power, the matching elasticity, the curvature of demand and the autoregressive parameter of labor productivity. As priors for standard deviations of errors, I choose inverse-gamma distributions with standard deviations of 0.5 percent for productivity, 1 percent for output and wages and 5 percent for all other variables. I run 10 blocks of 5000 iterations each from different starting points and target an acceptance rate of 30 percent.

\section{Results}

In this section I describe the posterior estimates and discuss their implications for calibration of labor matching models. I then evaluate the fit of the model along different dimensions and use values of the marginal density to evaluate the relative importance of the two key elements.

IV.1. Parameter Estimates. I report means and 90 percent confidence intervals of posterior estimates in Table 2. The matching elasticity is estimated to be 0.64 , close to Shimer's estimate of 0.72 . This is not surprising given that the parameter is identified in the same way through the relationship between the job finding rate and market tightness.

The posterior estimate of the bargaining power of workers, $\psi$, has a very wide confidence interval: from 27 percent to 61 percent. This implies that the value of bargaining power has little or no effect on the dynamic properties of the model. This confirms the analytical expressions described in equations (19)-(22) - only the way in which training costs are split matters. Since this effect is also accounted for by the parameter $\varphi$, the finding that bargaining power does not affect model performance is not at all surprising.

\footnotetext{
${ }^{17}$ This is consistent with the findings of Nagypal (2008, [25]) that only about 20 percent of all separations (which are approximately 10 percent per quarter) correspond to transitions from employment to unemployment. Also, according to the distribution of unemployment duration provided by the BLS, about 60 percent of all unemployed find jobs within a quarter, which is about 3 percent of the labor force in steady-state.
} 


\begin{tabular}{|l|l|l|l|c|}
\hline \multicolumn{2}{|l|}{ Parameter } & Prior & \multicolumn{2}{|c|}{ Posterior } \\
\hline & & Mean & Mean & $90 \%$ conf. interval \\
\hline Matching elasticity & $\alpha$ & 0.5 & 0.64 & {$\left[\begin{array}{lll}0.63 & 0.65\end{array}\right]$} \\
\hline Bargaining power of worker & $\psi$ & 0.5 & 0.42 & {$\left[\begin{array}{lll}0.27 & 0.61\end{array}\right]$} \\
\hline Curvature of demand & $\gamma$ & 0.5 & 0.13 & {$\left[\begin{array}{lll}0.07 & 0.20\end{array}\right]$} \\
\hline \hline Job destruction rate & $s$ & 0.03 & .0435 & {$[.0402, .0480]$} \\
\hline Fraction of training costs & $\varphi$ & 0.8 & 0.97 & {$\left[\begin{array}{lll}0.96 & 0.98\end{array}\right]$} \\
\hline Total costs & $\phi$ & 0.3 & 0.35 & {$\left[\begin{array}{lll}0.14 & 0.48\end{array}\right]$} \\
\hline \hline Persistence of productivity & $\rho$ & 0.5 & 0.91 & {$\left[\begin{array}{lll}0.86 & 0.94\end{array}\right]$} \\
\hline
\end{tabular}

TABle 2. Posterior Estimates

The only point at which the data that are directly affected by the bargaining power of the workers is the volatility of real wages. Like labor productivity, the series for real wages has a large measurement error, driven mostly by changes in the consumption price index, while nominal wages remain largely unchanged over the cycle. The model prefers to attribute most of variations in the wage series to measurement error rather than placing significant weight on its random movements.

The estimate for the total job creation cost, $\phi$, incurred by a firm lies in a wide range from 14 to 48 percent of quarterly wages of a new hire. The fraction of training costs and other costs specific to a match in total creation costs, $\varphi$, is tightly estimated at 97 percent. As noted before, the second parameter is key to explaining the behavior of vacancies and the negatively sloped Beveridge curve. Both of these parameters match quite closely the evidence presented by Silva and Toledo (2009, [32]). They estimate total costs to be between 36 and 55 percent of the quarterly wage of a new hire, with the fraction of training costs estimated at around 93 percent.

The result that bargaining power and the size of total job creation costs do not play a very important role in explaining the behavior of unemployment, vacancies and wages over the business cycle is in stark contrast with existing literature. One reason for this is the omission of the job destruction margin. When firms are not allowed to vary their firing activities, a much larger decline in the value of a match 
is required to explain the increase in unemployment through the job creation margin alone. When variations in match value are large, the bargaining power of a worker has to be unreasonably small to match low variability in wages. The other reason is the general equilibrium specification, which decouples the job creation cost parameter from variations in the value of the match, which are mainly driven by the curvature of preferences.

The estimate for the curvature of demand, $\gamma$, is at a surprisingly low value of $0.13^{18}$. However, a closer look at the implications of this value for the behavior of the value of a match clarifies its meaning. Substituting $\gamma=0.13, \rho=0.9$ and $\delta=1.6$ implied by the posterior mode into equation (19) gives a value of the elasticity of match value to an aggregate shock of 1.17. In the standard labor search model, this corresponds to a replacement rate of $0.15^{19}$. This is in the ballpark of the value of 0.4 used by Shimer and by studies of the effects of unemployment benefits and rigid wages, and much lower than the value of 0.95 used by Hagedorn and Manovskii.

I do a simple check for consistency of this parameter using its implications for the behavior of profits. Figure 5 in the Appendix compares the series for profits as a fraction of GDP predicted by the model with that observed for the U.S. economy. The prediction of the model matches remarkably well both the volatility and cyclicality of the profit series, even though the data for profits was not used in the estimation of the model.

Finally, the posterior mode of the average job destruction rate is estimated between 4 and 5 percent. This value is somewhat higher than the prior and implies a job finding rate of 70 to 85 percent. This is contrary to the finding of Cole and Rogerson (1999, [5]) that a relatively low job finding rate required to match data on job creation and job destruction implies counterfactually long duration of unemployment. Instead, the implied estimate of duration is at the lower bound of plausible duration values.

\footnotetext{
${ }^{18}$ The value of a match needs to fall to discourage firms from creating jobs or to encourage them to destroy more jobs. For the value of a match to fall in response to a negative aggregate shock the labor wedge has to be procyclical, which implies a value of $\gamma$ smaller than one.

${ }^{19}$ If $\frac{p}{p-z}=1.17$, then $z=1-\frac{1}{1.17}=0.15$.
} 
IV.2. Model Fit. To evaluate the fit of the model, I compare the second moments of the data with moments of artificial data generated by the model when hit by the estimated productivity shock. Table 3 compares standard deviations of seven observables of interest as well as their correlations with output. The results indicate that the model fits the data well, explaining virtually all of the fluctuations in vacancies, the job destruction and job finding rates, more than three-quarters of fluctuations in unemployment, and more than half of variations in job creation, with a single aggregate shock. The required variations in labor productivity and implied variations in wages are both of reasonable magnitude. Given the simplicity of the model this is a remarkable result.

The model matches well most of the cross correlations between observables with one exception. In the data job creation responds to aggregate shocks negatively at first and then rebounds slowly to rehire workers. The model predicts an immediate although slow positive response of job creation. When compared to the model, the data on job creation has a lag of about one or two quarters. This is essentially the only dimension on which the model doesn't perform well. The gap between wages in the model and in the data is satisfactory given that the discrepancy between the two commonly used series for real wages is large ${ }^{20}$. The series for labor productivity also has a large measurement error component.

To study the importance of the two key assumptions for model performance, I compare the performance of the benchmark model with five alternative specifications. In the first alternative specification, I set training costs to zero and re-estimate the model. In the second alternative specification, in addition to absence of training costs, I fix the job destruction rate at its steady-state level. The third alternative specification is the model of Lubik (2009, [21]), where jobs are destroyed exogenously at a constant rate, but non-linear job creation costs are allowed. In this specification I measure the joint explanatory power of shocks to productivity, preferences and

\footnotetext{
${ }^{20}$ The two commonly used series for real wages are average hourly earnings in private nonfarm payrolls divided by the consumption price index and the labor share times labor productivity. The root mean square difference between the two detrended series is $0.94 \log$ points which is comparable to average wage variability over the cycle of $0.97 \log$ points.
} 


\begin{tabular}{|l|c|c|c|c|c|c|c|c|}
\hline \multicolumn{10}{|c|}{ Standard Deviations } \\
\hline & $\mathrm{Y}$ & $\mathrm{U}$ & $\mathrm{V}$ & $\mathrm{JD}$ & $\mathrm{JC}$ & $\mathrm{JF}$ & $\mathrm{W}$ & $\mathrm{Y} / \mathrm{N}$ \\
\hline Data & 1.51 & 12.3 & 14.4 & 12.5 & 7.7 & 8.2 & 0.87 & 1.07 \\
\hline Model & 0.83 & 9.2 & 13.5 & 10.1 & 3.9 & 8.1 & 0.21 & 0.55 \\
\hline \multicolumn{10}{|c|}{ Procyclicality } \\
\hline Data & 1 & -0.81 & 0.81 & -0.64 & 0.26 & 0.77 & 0.19 & 0.49 \\
\hline Model & 1 & -0.99 & 0.99 & -0.37 & -0.98 & 0.99 & 0.99 & 0.99 \\
\hline
\end{tabular}

TABle 3. Comparison of Second Moments

markups ${ }^{21}$. Lubik applies similar methods to the same data on GDP, unemployment, vacancies and wages. He allows for exogenous shocks to preferences and market power, which are somewhat similar to the preference specification I use. Thus, this specification provides a comparable account for the explanatory power of a model with constant exogenous job destruction, but variable creation costs.

In the fourth alternative specification, I apply the same estimation strategy to Shimer's model allowing for variations in the value of the outside option and the bargaining weight. I denote this specification "H-M" because the resulting estimates replicate the calibration of Hagedorn and Manovskii (2008, [15]). The last specification is Shimer's original calibration.

Results of model comparison are summarized in Table 4. Numbers in the rows of Table 4 describe fractions of standard deviations of the data explained by the five alternative specifications and the benchmark specification. The last column computes the gain in marginal data density of each model compared to Shimer's original calibration. Marginal data density is a Bayesian analog of the Bayes information criterion, a robust means of model comparison, which uses the likelihood function as a measure of fit and penalizes the model for over-parametrization.

\footnotetext{
${ }^{21}$ The only residual source of variations not included is represented by shocks to matching efficiency
} 


\begin{tabular}{|l|c|c|c|c|c|c|c|c|}
\hline & \multicolumn{6}{|c|}{ Fraction of Variations Explained } & \\
\hline & $\mathrm{U}$ & $\mathrm{V}$ & $\mathrm{JD}$ & $\mathrm{JC}$ & $\mathrm{JF}$ & $\mathrm{W}$ & $\mathrm{Y} / \mathrm{N}$ & $\Delta \mathrm{MD}$ \\
\hline 0. Benchmark & .77 & .99 & .83 & .54 & .94 & .20 & .22 & 560 \\
\hline 1. K=0 & .76 & .06 & .79 & .43 & .88 & .29 & .30 & 222 \\
\hline 2. JD fixed & .41 & .98 & .00 & .61 & .79 & .23 & .26 & 307 \\
\hline 3. Lubik & .08 & .61 & .00 & - & - & .85 & - & - \\
\hline 4. H-M & .53 & .70 & .00 & .96 & .95 & .27 & .47 & 245 \\
\hline 5. Shimer & .07 & .09 & .00 & .11 & .06 & .77 & .79 & 0 \\
\hline
\end{tabular}

TABLE 4. Explanatory Power of Alternative Specifications

Comparison of lines 4 and 5 indicates that the calibration of Hagedorn and Manovskii, indeed, improves the performance of the labor search model, explaining half of variations in unemployment and 70 percent of variations in vacancies. Lubuk's specification in line 3 of the table demonstrates that even allowing for nonlinear job creation costs and adding other sources of fluctuations to the model does not improve the explanatory power of productivity shocks ${ }^{22}$. Line 2 confirms that a model with match-specific heterogeneity but without the job destruction margin or training costs has implications similar to that of line 4 .

Comparison of lines 0 and 1 to line 2 demonstrates that both the job destruction margin and training costs are key to the empirical performance of the benchmark model. Explaining variations in job destruction enhances the ability of the model to explain the behavior of unemployment, accounting for its initial increases during recessions. Incorporating training costs is crucial for explaining the decrease in vacancies and the sluggish response of job creation.

The explanatory power added by these two elements is more than two times larger than that produced by the H-M calibration. However the benchmark specification does not rely on the two most controversial assumptions: an extremely low value for job creation costs and low bargaining power of the worker. Instead, it matches very

\footnotetext{
${ }^{22}$ Direct introduction of training costs into Shimer's model under both calibrations does not alter its empirical performance and, therefore, is not reported.
} 
well empirical values for both the total job creation costs and the split of these costs into the recruiting and training components.

Additional dimensions where the benchmark model outperforms its predecessors are impulse response functions to a recessionary shock. Figure 4 compares impulse responses of four of the model specifications. Shimer's calibration generates almost no response to a recessionary shock. The calibration of Hagedorn and Manovskii explains about half of the response of unemployment, all of it through the job creation margin. Introduction of job destruction alone also explains a large fraction of fluctuations in unemployment, but is less satisfactory at explaining the behavior of vacancies. In fact, it generates countercyclical vacancy rates. The benchmark model explains, both quantitatively and qualitatively, a large fraction of the observed fluctuations in all of the variables of interest.

To my knowledge this model is the first incarnation of the MP model capable of generating realistic patterns of a large set of labor market variables as a result of a single aggregate shock of reasonable magnitude.

\section{CONCLUSION}

In this paper, I emphasize two elements of the Mortensen-Pissarides model: the job destruction margin and training costs. I show that these two elements enable the model to explain the sharp increases in unemployment and the large declines in job availability in recessions. I embed these two key elements into a general equilibrium model with a matching friction. I show that such a model driven by a single aggregate shock can simultaneously explain most variation in unemployment, vacancies, job creation, job destruction and the job finding rate, while remaining consistent with variability and cyclicality of profits, labor productivity and real wages. I estimate parameter values that provide the best fit of the data and find that they are all of plausible magnitude.

One desirable extension of this model is allowing on-the-job search and accounting for job-to-job transitions, which require modeling the persistence of the idiosyncratic 

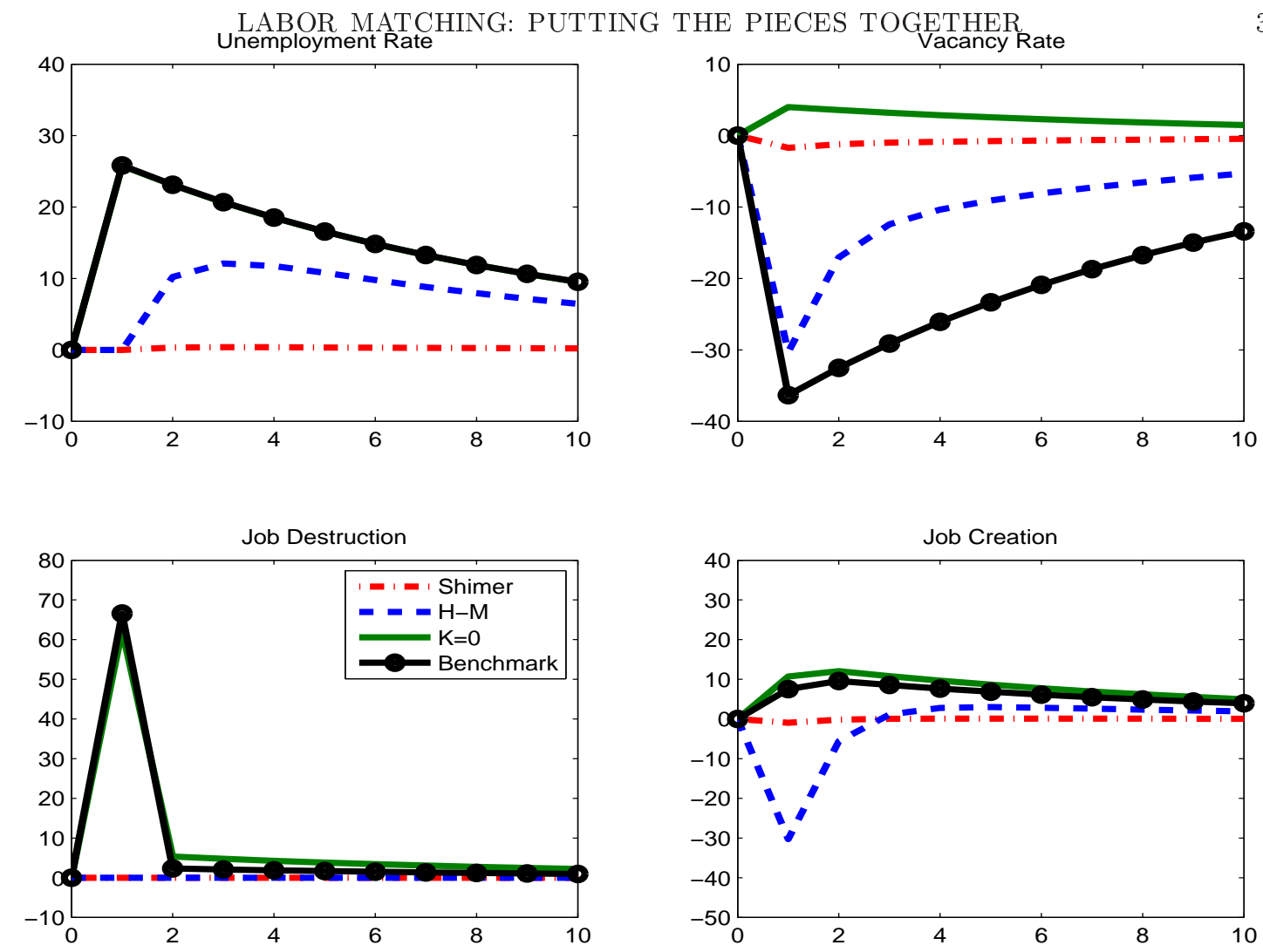

FiguRE 4. Impulse Responses of Alternative Specifications to a Recessionary Shock.

component of firm productivity. Another desirable extension of this model includes understanding the role of capital formation and the vintage effects of matches between capital and labor. A third important direction of further research is a plausible specification of the job creation process that allows for additional delays in creation and takes into account detailed microeconomic studies of creation costs. Cross-country analysis of job creation costs and their consequences for the slope of the Beveridge curve is another potential research topic.

Another potential line of research concerns the interaction of matching frictions with market power as discussed by Rotemberg (2006, [29]). Among the main unanswered questions are the sources of shocks driving the economy and the possibility of endogenous cycles in models with matching frictions. 


\section{REFERENCES}

[1] Sungbae An and Frank Schorfheide. Bayesian analysis of dsge models. Econometric Reviews, 26(2-4):113-172, 2007.

[2] Olivier Blanchard and Jordi Gali. Labor markets and monetary policy: A new keynesian model with unemployment. American Economic Journal: Macroeconomics, 2(2):1-30, April 2010.

[3] Ricardo J Caballero and Mohamad L Hammour. On the timing and efficiency of creative destruction. The Quarterly Journal of Economics, 111(3):805-52, August 1996.

[4] Anton Cheremukhin and Paulina Restrepo-Echavarria. The labor wedge as a matching friction. unpublished manuscript, 2009.

[5] Harold L. Cole and Richard Rogerson. Can the mortensen-pissarides matching model match the business-cycle facts? International Economic Review, 40(4):933-59, November 1999.

[6] F. Collard and M. Juillard. Stochastic simulations with dynare. a practical guide. Mimeo, 2003.

[7] Steven J. Davis, R. Jason Faberman, and John Haltiwanger. The flow approach to labor markets: New data sources and micro-macro links. Journal of Economic Perspectives, 20(3):3-26, Summer 2006.

[8] Steven J Davis and John C Haltiwanger. Gross job creation, gross job destruction, and employment reallocation. The Quarterly Journal of Economics, 107(3):81963, August 1992.

[9] Steven J. Davis, John C. Haltiwanger, and Scott Schuh. Job creation and destruction. The MIT Press, Cambridge, MA, pages 1-260, December 1997.

[10] Wouter J. den Haan, Garey Ramey, and Joel Watson. Job destruction and propagation of shocks. American Economic Review, 90(3):482-498, June 2000.

[11] Burcu Eyigungor. Specific capital and vintage effects on the dynamics of unemployment and vacancies. American Economic Review, 100(3):1214-37, June 2010 . 
[12] Roger E. A. Farmer and Andrew Hollenhorst. Shooting the auctioneer. NBER Working Paper, 12584, 2006.

[13] Mark Gertler and Antonella Trigari. Unemployment fluctuations with staggered nash wage bargaining. Journal of Political Economy, 117(1):38-86, 022009.

[14] John Geweke. Using simulation methods for bayesian econometric models: inference, development, and communication. Econometric Reviews, 18(1):1-73, 1999.

[15] Marcus Hagedorn and Iourii Manovskii. The cyclical behavior of equilibrium unemployment and vacancies revisited. American Economic Review, 98(4):16921706, September 2008.

[16] Robert E. Hall. Employment fluctuations with equilibrium wage stickiness. American Economic Review, 95(1):50-65, March 2005.

[17] Gary D. Hansen. Indivisible labor and the business cycle. Journal of Monetary Economics, 16(3):309-327, November 1985.

[18] Andreas Hornstein, Per Krusell, and Giovanni L. Violante. Unemployment and vacancy fluctuations in the matching model : inspecting the mechanism. Economic Quarterly, (Summer):19-50, 2005.

[19] Loukas Karabarbounis. Labor wedges and open economy puzzles.

[20] Michael Krause and Thomas A. Lubik. Does intra-firm bargaining matter for business cycle dynamics? Discussion Paper Series 1: Economic Studies 2007,17, Deutsche Bundesbank, Research Centre, 2007.

[21] Thomas A. Lubik. Estimating a search and matching model of the aggregate labor market. Economic Quarterly, 95(2):101-120, Spring 2009.

[22] Bruce D. Meyer. Unemployment insurance and unemployment spells. Econometrica, 58(4):757-82, July 1990.

[23] Dale T. Mortensen and Christopher A. Pissarides. Job creation and job destruction in the theory of unemployment. Review of Economic Studies, 61(3):397-415, July 1994.

[24] Dale T. Mortensen and Christopher A. Pissarides. Technological progress, job creation and job destruction. Review of Economic Dynamics, 1(4):733-753, October 1998. 
[25] Eva Nagypal. Worker reallocation over the business cycle: The importance of employer-to-employer transitions. Unpublished manuscript, 2008.

[26] Christopher A Pissarides. Search unemployment with on-the-job search. Review of Economic Studies, 61(3):457-75, July 1994.

[27] Christopher A. Pissarides. The unemployment volatility puzzle: Is wage stickiness the answer? Econometrica, 77(5):1339-1370, September 2009.

[28] Richard Rogerson. Indivisible labor, lotteries and equilibrium. Journal of Monetary Economics, 21(1):3-16, January 1988.

[29] Julio J. Rotemberg. Cyclical wages in a search-and-bargaining model with large firms. NBER Working Papers, WP(12415), August 2006.

[30] Robert Shimer. The cyclical behavior of equilibrium unemployment and vacancies. American Economic Review, 95(1):25-49, March 2005.

[31] Robert Shimer. Convergence in macroeconomics: The labor wedge. American Economic Journal: Macroeconomics, 1(1):280-97, January 2009.

[32] Jose Ignacio Silva and Manuel Toledo. Labor turnover costs and the cyclical behavior of vacancies and unemployment. Macroeconomic Dynamics, 13(S1):7696, May 2009.

[33] Christopher A. Sims. Solving linear rational expectations models. Computational Economics, 20(1-2):1-20, October 2002.

[34] Marcelo Veracierto. On the cyclical behavior of employment, unemployment and labor force participation. Journal of Monetary Economics, 55(6):1143-1157, September 2008.

[35] Eran Yashiv. Evaluating the performance of the search and matching model. European Economic Review, 50(4):909-936, May 2006.

\section{APPENDIX}

VI.1. Planner's solution. In this section I characterize the planner's solution for the model. I then compare it to the competitive equilibrium to draw conclusions about the optimal division of rents.

The planner maximizes utility: 


$$
\max _{\left\{q_{i t}, X_{t}, N_{t}, U_{t}, V_{t}, J_{t+1}\right\}} E_{0} \sum_{t=0}^{\infty} \beta^{t} u\left(C_{t}, N_{t}+X_{t}\right),
$$

where the consumption aggregator is defined as:

$$
C_{t}=\int_{0}^{N_{t}} z_{i t} q_{i t} d i
$$

and the taste shocks are drawn from:

$$
z_{i t}=e^{-g i}, \quad i \in \mathcal{U}\left[0, J_{t}\right],
$$

subject to the production technology:

$$
q_{i t}=A_{t},
$$

the headhunting technology:

$$
X_{t}=K M\left(U_{t}, V_{t}\right)+c V_{t}
$$

the job accumulation equation:

$$
J_{t+1}=N_{t}+M\left(U_{t}, V_{t}\right)
$$

and the constraint on time use:

$$
N_{t}+X_{t}+U_{t}=1
$$

I define Lagrange multipliers: $p_{i t}$ on production function of good $i, w_{t}$ on the headhunting technology, $\Gamma_{t}$ on the job accumulation constraint, and $\mu_{t}$ on time use, all multiplied by a common intertemporal Lagrange multiplier $\lambda_{t}$. Then the following first order conditions characterize the solution to the planner's problem. The value of product $i$ satisfies:

$$
p_{i t}=\frac{u_{C_{t}}^{\prime}}{\lambda_{t}} z_{i t}
$$

the value of a job: 


$$
\Gamma_{t}=E_{i t} \beta \frac{\lambda_{t+1}}{\lambda_{t}}\left\{\frac{u_{C_{t+1}}^{\prime}}{\lambda_{t+1}} z_{i, t+1} q_{i, t+1}+\frac{u_{N_{t+1}}^{\prime}}{\lambda_{t+1}}-\mu_{t+1}+\Gamma_{t+1}, 0\right\},
$$

the optimal rate of productive employment:

$$
\left.\frac{u_{C_{t}}^{\prime}}{\lambda_{t}} z_{i, t} q_{i, t}\right|_{i=N_{t}}+\frac{u_{N_{t}}^{\prime}}{\lambda_{t}}-\mu_{t}+\Gamma_{t}=0,
$$

the value of an unemployed:

$$
\mu_{t}=\left(\Gamma_{t}-w_{t} K\right) \frac{\partial M}{\partial U_{t}}
$$

the value of a headhunter:

$$
w_{t}=-\frac{u_{X_{t}}^{\prime}}{\lambda_{t}}+\mu_{t}
$$

and the optimal number of vacancies:

$$
w_{t} c=\left(\Gamma_{t}-w_{t} K\right) \frac{\partial M_{t}}{\partial V_{t}} .
$$

Substituting the value of an unemployed into the value of a headhunter leads to:

$$
w_{t}=-\frac{u_{X_{t}}^{\prime}}{\lambda_{t}}+\left(\Gamma_{t}-w_{t} K\right) \frac{\partial M}{\partial U_{t}},
$$

Most of the equations of the planner's solution already coincide with equations that characterize the competitive equilibrium. The only difference comes from equations (25) and (26). From comparing them to equations (17) and (11) it follows that the competitive equilibrium is Pareto-optimal if and only if the Hosios condition is satisfied:

$$
\psi \frac{\partial M}{\partial V_{t}} \frac{V_{t}}{M_{t}}=\frac{\partial M}{\partial U_{t}} \frac{U_{t}}{M_{t}}(1-\psi)
$$

For a Cobb-Douglas matching function used in the model this simplifies to:

$$
\psi=\frac{\partial M}{\partial U_{t}} \frac{U_{t}}{M_{t}}=\alpha
$$


VI.2. Computation of the Steady-state. For the general derivation I use a general specification of preferences:

$$
u\left(C_{t}, N_{t}+X_{t}\right)=\frac{C_{t}^{1-\gamma}-1}{1-\gamma}-\varpi \frac{\left(N_{t}+X_{t}\right)^{1+\eta}}{1+\eta}
$$

The system of equations of the model can then be reduced to:

(1) $\quad A_{t}=A_{s s}^{1-\rho} A_{t-1}^{\rho} e^{\sigma \varepsilon_{t}} \quad \varepsilon_{t} \in \mathcal{N}(0,1)$

(2) $\quad M_{t}=B U_{t}^{\alpha} V_{t}^{1-\alpha}$

(3) $U_{t}=1-N_{t}-X_{t}$

(4) $X_{t}=c V_{t}+K M_{t}$

(5) $\quad J_{t+1}=N_{t}+M_{t}$

(6) $\quad N_{t}=J_{t}\left(1-\zeta_{t}\right)$

(7) $\quad P_{t}=\frac{1}{\lambda_{t}} C_{t}^{-\gamma}$

(8) $C_{t}=A_{t} \frac{1-e^{-g N_{t}}}{g}$

(9) $w_{t}=\frac{\varpi\left(N_{t}+X_{t}\right)^{\eta}}{\lambda_{t}}+\psi\left(\Gamma_{t}-K w_{t}\right) \frac{M_{t}}{U_{t}}$

(10) $\quad c w_{t}=(1-\psi)\left(\Gamma_{t}-K w_{t}\right) \frac{M_{t}}{V_{t}}$

(11) $\Gamma_{t}=E_{t} \beta \frac{\lambda_{t+1}}{\lambda_{t}}\left(\frac{P_{t+1} C_{t+1}}{N_{t+1}}-w_{t+1}+\Gamma_{t+1}\right)$

(12) $P_{t} A_{t} e^{-g N_{t}}-w_{t}+\Gamma_{t}=0$

(13) $\frac{W_{t}}{P_{t}}=\psi \frac{C_{t}}{N_{t}}+(1-\psi) \frac{w_{t}}{P_{t}}$

(14) $\frac{\text { Profit }}{G D P}=\frac{\Pi_{t}}{P_{t} C_{t}}=(1-\psi)\left(1-\frac{w_{t} N_{t}}{P_{t} C_{t}}\right)$

where $\left\{A_{t}, J_{t}, N_{t}, M_{t}, U_{t}, X_{t}, V_{t}, \lambda_{t}, P_{t}, C_{t}, \Gamma_{t}, \zeta_{t}, W_{t}, \Pi_{t}\right\}$ are the endogenous variables of the model, $w_{t}=1$ is the numeraire and $\varepsilon_{t}$ is the exogenous shock.

The structural parameters of the model are:

$$
\{\beta, \gamma, \psi, \alpha, \rho, \sigma\} \quad\left\{c, K, g, A_{s s}\right\} \quad\{B\} \quad\{\eta, \varpi\}
$$

There is a one-to-one mapping between:

$$
\begin{aligned}
& \left\{c, K, g, A_{s s}\right\} \Leftrightarrow\left\{s=\zeta_{s s}, \varphi=\frac{K M_{s s}(1-\psi)}{c V_{s s}+K M_{s s}(1-\psi)}, \phi=\frac{c \frac{V}{M}+K(1-\psi)}{\psi \frac{P C}{N}+1-\psi}, u=U_{s s}\right\} \quad \text { and }\{B\} \Leftrightarrow \\
& \left\{v f=\frac{M_{s s}}{V_{s s}}\right\}
\end{aligned}
$$

To compute the steady-state I follow the following steps:
a) $\varphi_{2}=\frac{\varphi}{(1-\varphi)(1-\psi)+\varphi}$
b) $\Gamma=\frac{1}{\frac{1-\psi}{\phi}-\psi\left(\frac{1}{\beta}-1\right)} \quad \pi=\frac{1}{\left(\frac{1-\varphi_{2}}{1-\psi}+\varphi_{2}\right) \frac{1-\zeta}{\zeta} \frac{1}{\Gamma}+1}$
c) $N=(1-U)(1-\pi) \quad M=\frac{\zeta}{1-\zeta} N \quad V=\frac{M}{v f}$ 
d) $X=(1-U) \pi \quad J=\frac{N}{1-\zeta}$

I plug these values into a numerical solver to find $g$ that satisfies:

e) $1=\frac{e^{g N}-1}{g N} \frac{1-\Gamma}{1+\left(\frac{1}{\beta}-1\right) \Gamma}$

I then compute:

f) $\mu=(1-\Gamma) e^{g N} \quad c=\left(1-\varphi_{2}\right) \frac{X}{M} \frac{M}{V} \quad K=\varphi_{2} \frac{X}{M}$

g) $B=\frac{M}{U^{\alpha} V^{1-\alpha}} \quad \lambda=\frac{\varpi(1-U)^{\eta}}{1-\frac{b}{w}-\frac{\psi}{1-\psi} \frac{V}{U} c}$

h) $A=\left[\mu \lambda\left(\frac{1-e^{-g N}}{g}\right)^{\gamma}\right]^{\frac{1}{1-\gamma}} \quad C=A \frac{1-e^{-g N}}{g}$

i) $P=\frac{1}{\lambda} C^{-\gamma} \quad \frac{W}{P}=\psi \frac{C}{N}+(1-\psi) \frac{1}{P} \quad \frac{\text { Profit }}{G D P}=1-\frac{N}{P C}$

VI.3. Derivation of the Beveridge Curve. I linearize the reduced system of equations above to obtain:

$\left(1^{\prime}\right) \quad a_{t}=\rho a_{t-1}+\sigma \varepsilon_{t}$

$\left(2^{\prime}\right) \quad m_{t}=\alpha u_{t}+(1-\alpha) v_{t}$

$\left(3^{\prime}\right) \quad(1-\pi) n_{t}+\pi x_{t}=-\kappa u_{t}$

$\left(4^{\prime}\right) \quad x_{t}=(1-\varphi) v_{t}+\varphi m_{t}$

$\left(5^{\prime}\right) \quad j_{t+1}=n_{t}(1-s)+s m_{t}$

$\left(6^{\prime}\right) \quad n_{t}=j_{t}-\frac{s}{1-s} s_{t}$

$\left(7^{\prime}\right) \quad p_{t}=-\gamma c_{t}-\lambda_{t}$

$\left(8^{\prime}\right) \quad c_{t}=a_{t}+n_{t}$

$\left(9^{\prime}\right) \quad \lambda_{t}=\eta\left((1-\pi) n_{t}+\pi x_{t}\right)-\varsigma\left(v_{t}-u_{t}\right)$

$\left(10^{\prime}\right) \quad g_{t}=\left(1-\varphi_{2}\right)\left(v_{t}-m_{t}\right)$

$$
g_{t}=E_{t}\left(a_{t+1}+p_{t+1}+n_{t+1}+\lambda_{t+1}\right)-\lambda_{t}
$$$$
g_{t}=\chi\left(a_{t}+p_{t}-\delta n_{t}\right)
$$

where I introduce new notation:

$\kappa=\frac{U}{1-U} \quad s=\frac{M}{N} \quad \varphi_{2}=\frac{K M}{c V+K M}$

$\eta, \quad \rho, \quad \Lambda=\frac{X}{M} \approx \frac{\delta}{2} \frac{\varphi_{2}}{\varphi} \frac{1}{1-s} \quad \pi=\frac{s \Lambda}{1+s \Lambda}$

$\varsigma=\frac{1}{\frac{1-\psi}{\psi} \frac{\kappa}{\pi} \frac{1}{1-\varphi}-1} \quad \frac{-1}{\chi}=\frac{1}{\frac{1-\pi}{\pi} \frac{s}{1-s} \frac{\varphi}{\varphi_{2}}-1}$

$1-\Gamma=\frac{1}{1-\frac{1}{\chi}}=1-\frac{\pi}{1-\pi} \frac{1-s}{s} \frac{\varphi_{2}}{\varphi}=1-\Lambda(1-s) \frac{\varphi_{2}}{\varphi}$

$\delta=\frac{z_{\max }}{z_{\min }} \quad 1+\delta=\exp (g N) \approx \frac{\mu}{1-\Lambda(1-s) \frac{\varphi_{2}}{\varphi}}$

I then combine the linearized equations to derive the Beveridge curve:

Substitute $\left(2^{\prime}\right) \quad m_{t}=\alpha u_{t}+(1-\alpha) v_{t}$ 
Substitute $\left(4^{\prime}\right) \quad x_{t}=(1-\varphi) v_{t}+\varphi\left(\alpha u_{t}+(1-\alpha) v_{t}\right)$

Solve for $v_{t}$ and $u_{t}$ :

$$
\begin{aligned}
& (1-\pi) n_{t}+\pi\left((1-\varphi) v_{t}+\varphi\left(\alpha u_{t}+(1-\alpha) v_{t}\right)\right)=-\kappa u_{t} \\
& g_{t}=\left(1-\varphi_{2}\right)\left(v_{t}-\alpha u_{t}-(1-\alpha) v_{t}\right)
\end{aligned}
$$

Hence,

$$
\begin{aligned}
& v_{t}=\frac{g_{t}}{\left(1-\varphi_{2}\right) \alpha}+u_{t} \\
& u_{t}=-\frac{1-\pi}{\pi+\kappa} n_{t}-\frac{\pi}{\pi+\kappa} \frac{(1-\varphi \alpha)}{\left(1-\varphi_{2}\right) \alpha} g_{t} \\
& v_{t}=-\frac{1-\pi}{\pi+\kappa} n_{t}+\left(\frac{1}{1-\varphi \alpha}-\frac{\pi}{\pi+\kappa}\right) \frac{(1-\varphi \alpha)}{\left(1-\varphi_{2}\right) \alpha} g_{t} \\
& \frac{v_{t}}{u_{t}}=1-\frac{\kappa(1+s \Lambda)+s \Lambda}{\left(1-\varphi_{2}\right) \alpha \frac{n_{t}}{g_{t}}+s \Lambda(1-\varphi \alpha)} \\
& m_{t}=u_{t}+(1-\alpha)\left(v_{t}-u_{t}\right)=-\frac{1-\pi}{\pi+\kappa} n_{t}+\left(\frac{1-\alpha}{1-\varphi \alpha}-\frac{\pi}{\pi+\kappa}\right) \frac{(1-\varphi \alpha)}{\left(1-\varphi_{2}\right) \alpha} g_{t} \\
& x_{t}=u_{t}+(1-\varphi \alpha)\left(v_{t}-u_{t}\right)=-\frac{1-\pi}{\pi+\kappa} n_{t}+\left(1-\frac{\pi}{\pi+\kappa}\right) \frac{1-\varphi \alpha}{\left(1-\varphi_{2}\right) \alpha} g_{t}
\end{aligned}
$$

Substitute in $\left(9^{\prime}\right)$ :

$\lambda_{t}=\eta\left(\frac{\kappa-\pi \kappa}{\kappa+\pi} n_{t}+\frac{\frac{\pi \kappa}{\pi+\kappa}(1-\varphi \alpha)-\frac{\varsigma}{\eta}}{\left(1-\varphi_{2}\right) \alpha} g_{t}\right)$

Substitute $p_{t}, c_{t}$ from $\left(7^{\prime}\right)$ and $\left(8^{\prime}\right)$ into $\left(11^{\prime}\right)$ and $\left(12^{\prime}\right)$ :

$g_{t}=E_{t}\left(a_{t+1}-\gamma c_{t+1}+n_{t+1}\right)-\lambda_{t}=(1-\gamma) E_{t}\left(a_{t+1}+n_{t+1}\right)-\lambda_{t}$

$g_{t}=\chi\left(a_{t}-\gamma c_{t}-\delta n_{t}-\lambda_{t}\right)=\chi\left((1-\gamma) a_{t}-(\gamma+\delta) n_{t}\right)-\chi \lambda_{t}$

Substitute $\lambda_{t}$ from above:

$$
\begin{aligned}
& \left(1+\eta \frac{\frac{\pi \kappa}{\pi+\kappa}(1-\varphi \alpha)-\frac{\varsigma}{\eta}}{\left(1-\varphi_{2}\right) \alpha}\right) g_{t}+\eta \frac{\kappa-\pi \kappa}{\kappa+\pi} n_{t}=(1-\gamma) E_{t}\left(a_{t+1}+n_{t+1}\right) \\
& \left(\frac{1}{\chi}+\eta \frac{\frac{\pi \kappa}{\pi+\kappa}(1-\varphi \alpha)-\frac{\varsigma}{\eta}}{\left(1-\varphi_{2}\right) \alpha}\right) g_{t}+\eta \frac{\kappa-\pi \kappa}{\kappa+\pi} n_{t}=(1-\gamma) a_{t}-(\gamma+\delta) n_{t}
\end{aligned}
$$

We can get rid of $g_{t}$ and get a single forward-looking equation in $n_{t}$ :

$g_{t}=\frac{(1-\gamma) a_{t}-(\gamma+\delta) n_{t}-\eta \frac{\kappa-\pi \kappa}{\kappa+\pi} n_{t}}{\left(\frac{1}{\chi}+\eta \frac{\frac{\pi \kappa}{\pi+\kappa}(1-\varphi \alpha)-\frac{\varsigma}{\eta}}{\left(1-\varphi_{2}\right) \alpha}\right)} \quad$ denote $\varrho=\frac{1+\eta \frac{\frac{\pi \kappa}{\pi+\kappa}(1-\varphi \alpha)-\frac{\varsigma}{\eta}}{\frac{\pi\left(1-\varphi_{2}\right) \alpha}{\chi}}}{\frac{1}{\chi}+\eta \frac{\frac{\pi}{\pi+\kappa}(1-\varphi \alpha)-\frac{\varsigma}{\eta}}{\left(1-\varphi_{2}\right) \alpha}}$

$\varrho\left((1-\gamma) a_{t}-(\gamma+\delta) n_{t}-\eta \frac{\kappa-\pi \kappa}{\kappa+\pi} n_{t}\right)+\eta \frac{\kappa-\pi \kappa}{\kappa+\pi} n_{t}=(1-\gamma) E_{t}\left(a_{t+1}+n_{t+1}\right)$

Guess solution: $\quad n_{t}=\tau a_{t}$

Then applying the expectations operator yields: $\quad E_{t} a_{t+1}=\rho a_{t}$

Therefore, $n_{t}$ is a jump variable $E_{t} n_{t+1}=E_{t} \tau a_{t+1}=\tau \rho a_{t}=\rho n_{t}$

Solve for $\tau$ :

$$
\begin{aligned}
& \varrho\left((1-\gamma)-(\gamma+\delta) \tau-\eta \frac{\kappa-\pi \kappa}{\kappa+\pi} \tau\right)=(1-\gamma) \rho(1+\tau)-\eta \frac{\kappa-\pi \kappa}{\kappa+\pi} \tau \\
& \frac{n_{t}}{a_{t}}=\tau=\frac{(1-\gamma)\left(1-\frac{\rho}{\varrho}\right)}{\gamma+\delta+(1-\gamma) \rho \frac{1}{\varrho}+\left(1-\frac{1}{\varrho}\right) \eta \frac{\kappa(1-\pi)}{\kappa+\pi}} \approx \frac{1-\gamma}{\gamma+\delta}
\end{aligned}
$$

In what follows the approximation is for $\pi \rightarrow 0, \eta=0$. Substitute to get: 


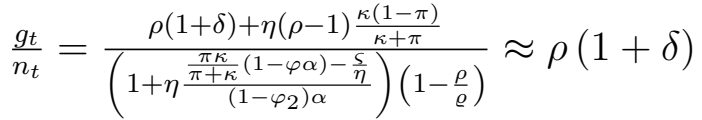

$$
\begin{aligned}
& \frac{u_{t}}{a_{t}}=-\left(\frac{1-\pi}{\pi+\kappa}+\frac{\pi}{\pi+\kappa} \frac{(1-\varphi \alpha)}{\left(1-\varphi_{2}\right) \alpha} \frac{g_{t}}{n_{t}}\right) \frac{n_{t}}{a_{t}} \approx-\frac{1}{\kappa} \frac{1-\gamma}{\gamma+\delta} \\
& \frac{v_{t}}{a_{t}}=\left(-\frac{1-\pi}{\pi+\kappa}+\left(\frac{1}{1-\varphi \alpha}-\frac{\pi}{\pi+\kappa}\right) \frac{1-\varphi \alpha}{\left(1-\varphi_{2}\right) \alpha} \frac{g_{t}}{n_{t}}\right) \frac{n_{t}}{a_{t}} \approx-\frac{1}{\kappa}\left(1-\frac{\kappa \rho(1+\delta)}{\left(1-\varphi_{2}\right) \alpha}\right) \frac{1-\gamma}{\gamma+\delta} \\
& \frac{m_{t}}{a_{t}}=\left(-\frac{1-\pi}{\pi+\kappa}+\left(\frac{1-\alpha}{1-\varphi \alpha}-\frac{\pi}{\pi+\kappa}\right) \frac{1-\varphi \alpha}{\left(1-\varphi_{2}\right) \alpha} \frac{g_{t}}{n_{t}}\right) \frac{n_{t}}{a_{t}} \approx-\frac{1}{\kappa}\left(1-\frac{(1-\alpha) \kappa \rho(1+\delta)}{\left(1-\varphi_{2}\right) \alpha}\right) \frac{1-\gamma}{\gamma+\delta} \\
& \frac{x_{t}}{a_{t}}=\left(-\frac{1-\pi}{\pi+\kappa}+\left(1-\frac{\pi}{\pi+\kappa}\right) \frac{1-\varphi \alpha}{\left(1-\varphi_{2}\right) \alpha} \frac{g_{t}}{n_{t}}\right) \frac{n_{t}}{a_{t}} \approx-\frac{1}{\kappa}\left(1-\frac{(1-\varphi \alpha) \kappa \rho(1+\delta)}{\left(1-\varphi_{2}\right) \alpha}\right) \frac{1-\gamma}{\gamma+\delta} \\
& \frac{v_{t}}{u_{t}}=1-\frac{\kappa(1+s \Lambda)+s \Lambda}{\left(1-\varphi_{2}\right) \alpha \frac{n_{t}}{g_{t}}+s \Lambda(1-\varphi \alpha)} \approx 1-\frac{\kappa \rho(1+\delta)}{\left(1-\varphi_{2}\right) \alpha}
\end{aligned}
$$

Job destruction (on impact):

$\frac{s_{t}}{a_{t}}=\frac{1-s}{s} \frac{j_{t}-n_{t}}{a_{t}}=-\frac{1-s}{s} \frac{n_{t}}{a_{t}} \approx-\frac{1-s}{s} \frac{1-\gamma}{\gamma+\delta}$ 
Moments of the Data

\begin{tabular}{|l|l|l|l|l|l|l|l|l|}
\hline std & 1.54 & 13.0 & 14.4 & 12.5 & 7.7 & 8.2 & 0.87 & 1.07 \\
\hline corr & $\mathrm{Y}$ & $\mathrm{U}$ & $\mathrm{V}$ & $\mathrm{JD}$ & $\mathrm{JC}$ & $\mathrm{JF}$ & $\mathrm{W}$ & $\mathrm{Y} / \mathrm{N}$ \\
\hline GDP & & -0.81 & 0.81 & -0.64 & 0.26 & 0.77 & 0.19 & 0.49 \\
\hline $\mathrm{U}$ & & & -0.95 & 0.43 & 0.01 & -0.93 & -0.10 & -0.02 \\
\hline $\mathrm{V}$ & & & & -0.49 & 0.05 & 0.92 & 0.16 & 0.08 \\
\hline JD & & & & & -0.59 & -0.44 & -0.25 & -0.53 \\
\hline JC & & & & & & 0.08 & 0.08 & 0.36 \\
\hline JF & & & & & & & 0.09 & 0.02 \\
\hline W & & & & & & & & 0.43 \\
\hline
\end{tabular}

Model Generated Moments

\begin{tabular}{|l|l|l|l|l|l|l|l|l|}
\hline std & 0.83 & 9.2 & 13.5 & 10.1 & 3.9 & 8.1 & 0.21 & 0.55 \\
\hline corr & $\mathrm{Y}$ & $\mathrm{U}$ & $\mathrm{V}$ & $\mathrm{JD}$ & $\mathrm{JC}$ & $\mathrm{JF}$ & $\mathrm{W}$ & $\mathrm{Y} / \mathrm{N}$ \\
\hline GDP & & -0.99 & 0.99 & -0.37 & -0.98 & 0.99 & 0.99 & 0.99 \\
\hline U & & & -0.98 & 0.36 & 0.99 & -0.99 & -0.99 & -0.99 \\
\hline V & & & & -0.38 & -0.97 & 0.99 & 0.98 & 0.99 \\
\hline JD & & & & & 0.24 & -0.38 & -0.38 & -0.40 \\
\hline JC & & & & & & -0.98 & -0.97 & -0.98 \\
\hline JF & & & & & & & 0.99 & 0.99 \\
\hline JF & & & & & & & & 0.99 \\
\hline
\end{tabular}

TABle 5. Moments of the Data vs Model 

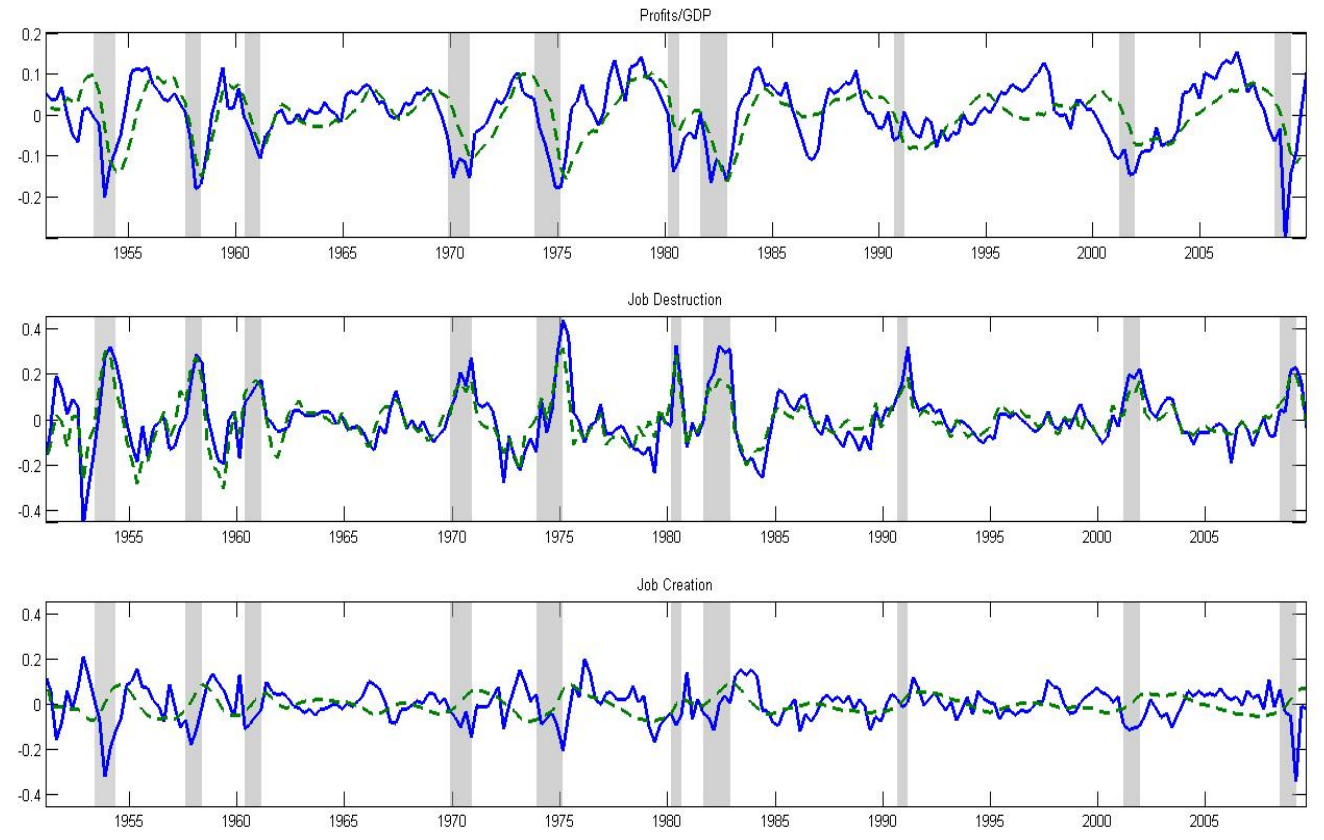

Figure 5. Fit of Profits, Job Destruction and Job Creation.
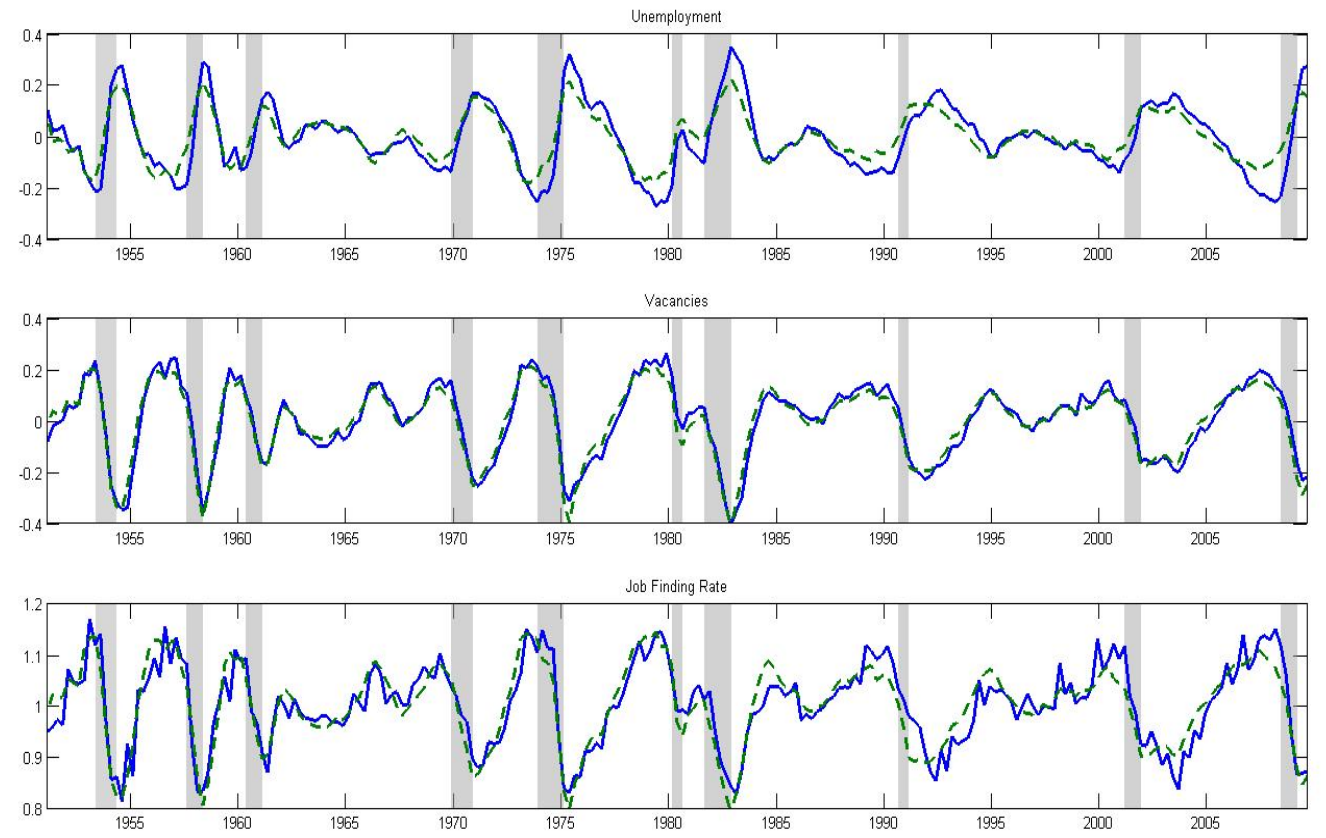

Figure 6. Fit of Unemployment, Vacancies and the Job Finding Rate. 

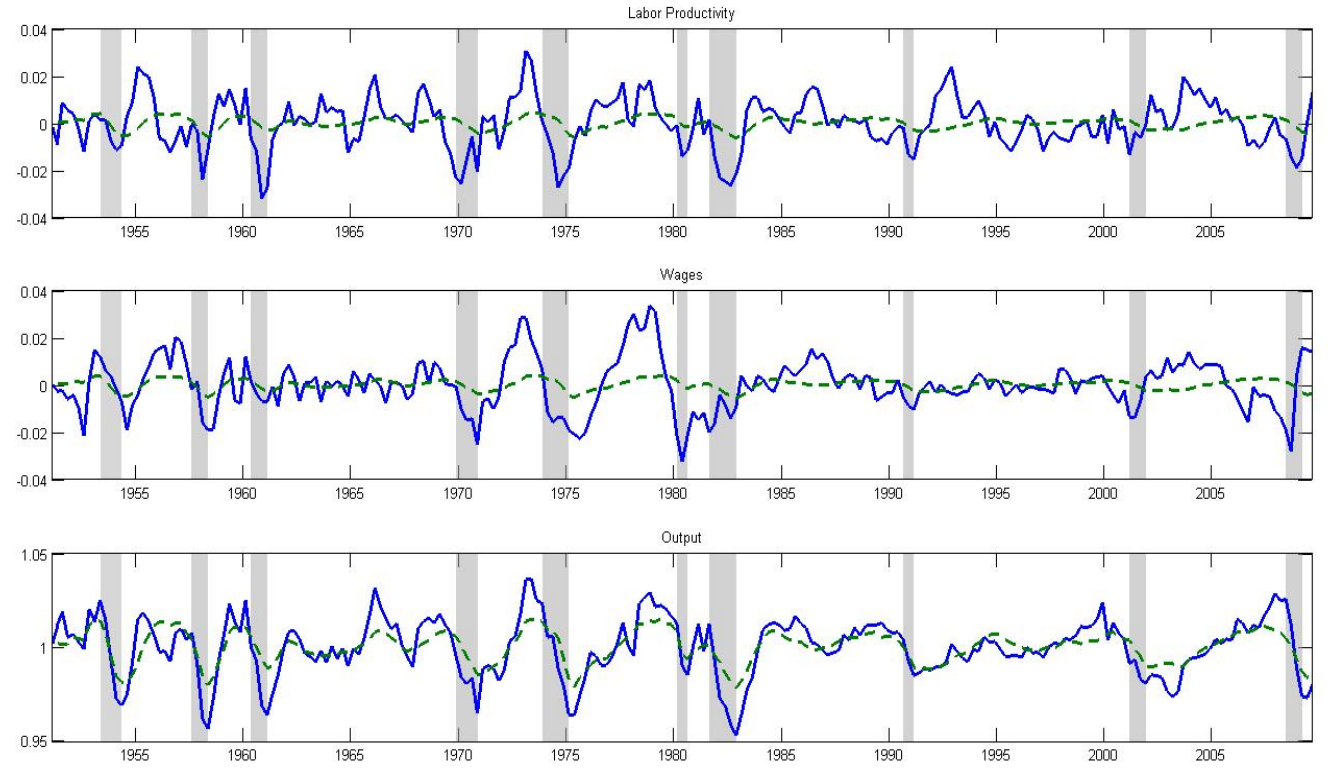

Figure 7. Fit of Productivity, Wages and Output.
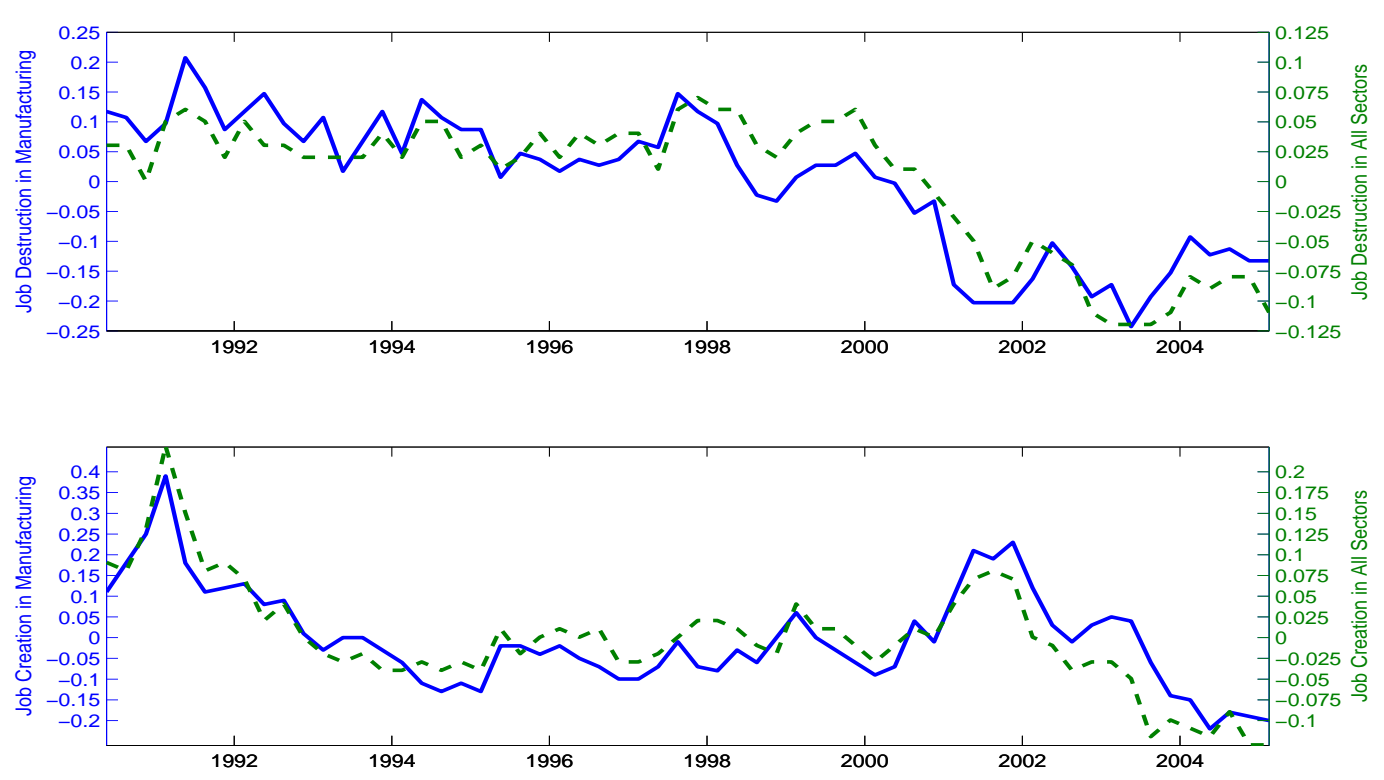

Figure 8. Comparison of Creation and Destruction for Manufacturing and All Sectors. 

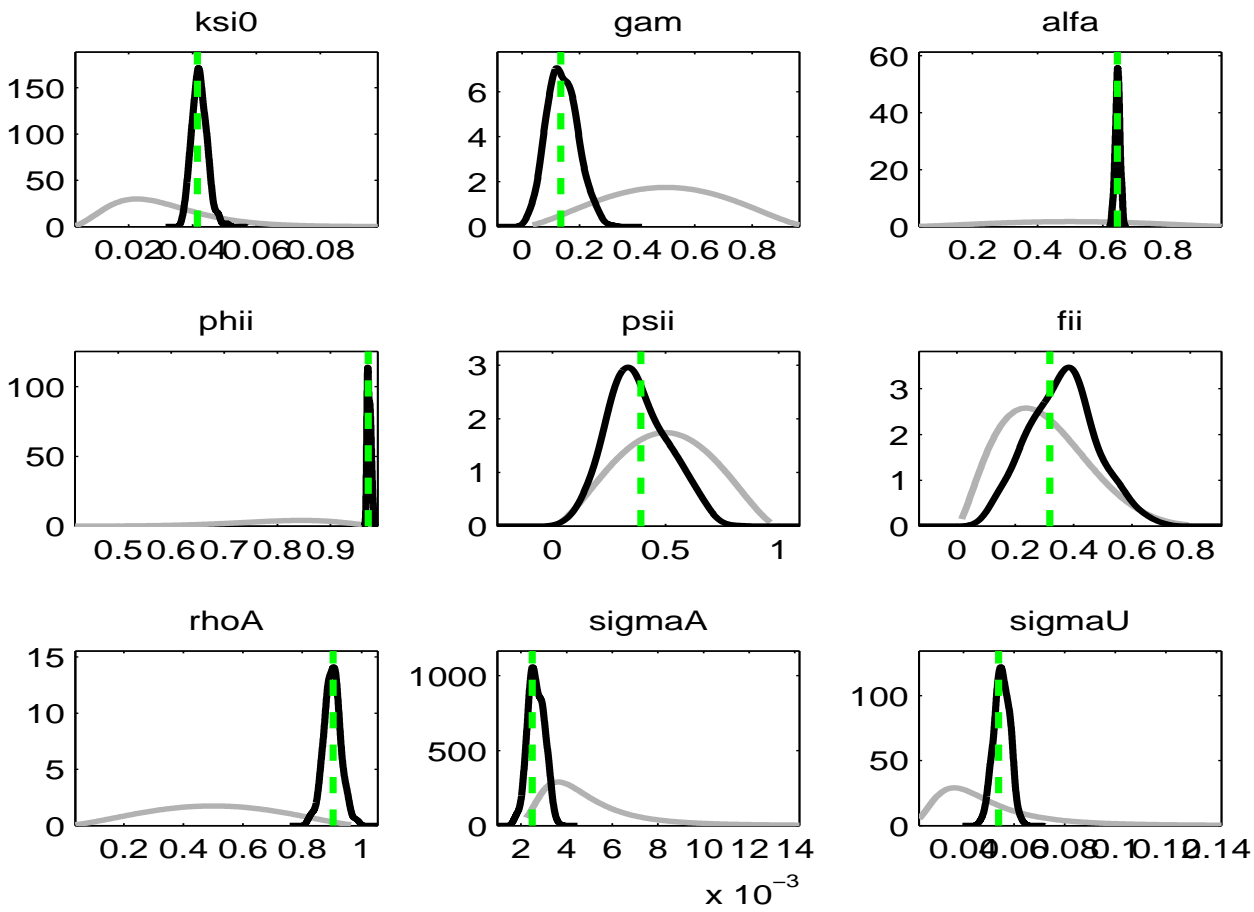

sigmaV
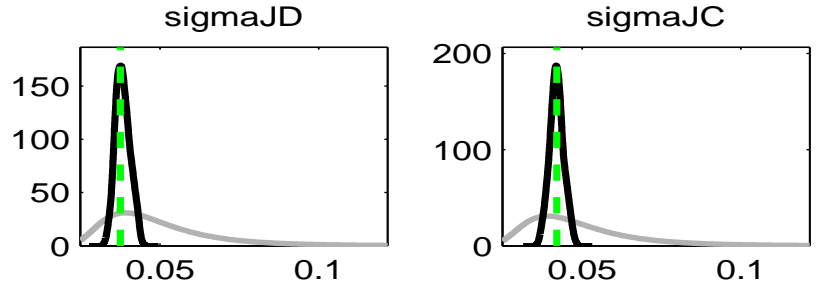

sigmaJF

sigmaW
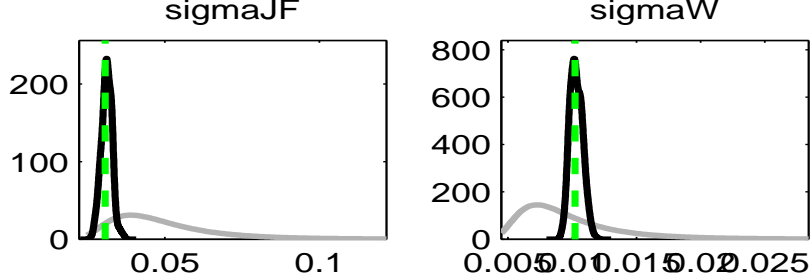

sigmaP

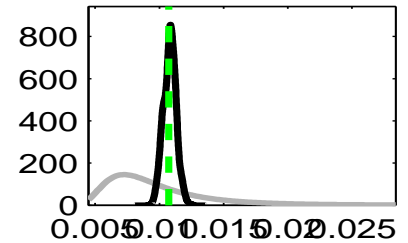

Figure 9. Comparison of Prior and Posterior Distributions. 